\title{
Re-Examining the Impact of Multidimensional Trust on Patients' Online Medical Consultation Service Continuance Decision
}

\author{
Ming Yang ${ }^{1} \cdot$ Jinglu Jiang ${ }^{2}$ (I) $\cdot$ Melody Kiang $^{3} \cdot$ Fangyun Yuan $^{1}$ \\ Accepted: 11 February 2021 / Published online: 4 March 2021 \\ (C) The Author(s), under exclusive licence to Springer Science+Business Media, LLC, part of Springer Nature 2021
}

\begin{abstract}
Recent years have witnessed the rapid growth of an emerging digital healthcare service - online medical consultation $(\mathrm{OMC})$. Despite its popularity, many OMC platforms have encountered issues in initial adoption and continuance use among patients. We posit that many of the hesitation and resistance may arise from a lack of trust toward OMC, which is a complex phenomenon that involves both interpersonal and technological-oriented considerations. This study seeks to clarify the conceptualization of online trust in the context of OMC. It compares two plausible explanations (i.e., trust as a direct cause vs. trust as a moderator) regarding how interpersonal and technological trust contributes to the service continuance decision in OMC. By contextualizing the valence framework, we identify the critical factors in making the risk-benefit assessment of patients' OMC decision. We conduct an online survey of 365 experienced OMC users and analyze our structural model using a partial least square approach. Our results show that the multidimensional conceptualization approach, which incorporates both interpersonal and technological aspects of trust, is superior to the unitary approach. Besides, our findings suggest that the role trust plays in determining service continuance decisions in OMC is more of a direct cause than a qualifier that buffers the impacts of risk-benefit evaluation. We believe the findings can help both researchers and practitioners recognize the multidimensional perspective of trust and better understand the role trust plays in OMC and other online healthcare delivery problems.
\end{abstract}

Keywords Online trust $\cdot$ Online healthcare consultation $\cdot$ Digital platform $\cdot$ Multidimensionality $\cdot$ Valence framework $\cdot$ Partial least square

Jinglu Jiang

jingluj@binghamton.edu

Ming Yang

yangming@cufe.edu.cn

Melody Kiang

mkiang@csulb.edu

Fangyun Yuan

yunyunyun0828@163.com

1 School of Information, Central University of Finance and Economics, Beijing 100081, China

2 School of Management, SUNY-Binghamton University, Binghamton, NY 13902, USA

3 Department of Information System, California State University, Long Beach, CA 90840, USA

\section{Introduction}

The use of online medical consultation (OMC) - a type of online healthcare provided by qualified healthcare professionals on third-party digital platforms - has been growing in recent years. According to a user survey by Kantar Health in China, ${ }^{1}$ during the COVID-19 pandemic, around $15 \%$ of patients have been using online medical consultation platforms for healthcare information seeking, diagnosis, and treatment. Despite the popularity of such services, many OMC platforms have difficulties attracting active participation and continuous payment, limiting the platforms' sustainability (Zhang et al. 2019). We posit that the hesitation and resistance in the service continuance among OMC patients are largely due to the lack of trust in various aspects of OMC services (Yang et al. 2020). With the digital transformation of medical

\footnotetext{
${ }^{1}$ KantarHealth. Health awareness and behaviors WeChat survey. 2020 [cited 2020; Available from: https://cn-en.kantar.com/business/health/2020/healthawareness-and-behaviors-during-covid-19-epidemic/.
} 
procedures on $\mathrm{OMC}$, trust becomes an ever-complex issue in that no face-to-face interaction exists to fertilize patients' belief in healthcare providers' reliability and the ability to provide professional services. Consequently, patients may abandon the service due to a lack of trust, and high-quality doctors may also quit the platform if there is no sufficient number of OMC orders and economic returns.

Previous studies in OMC patient retention generally focus on the impacts of service characteristics and physician qualities on patients' physician selection process (Cao et al. 2017; Liu et al. 2016), whereas the underlying psychological mechanisms relating to patient's decision on continuing the service with a doctor remain mostly an under-researched area. We start our investigation with online trust to narrow this research gap, which is an established mechanism explaining online transaction success (Chiu et al. 2012; Fang et al. 2014; Torkzadeh and Dhillon 2002; Xu et al. 2016).

Trust is especially critical in OMC for several reasons. First, $\mathrm{OMC}$ is a type of online transaction that requires patients to submit various sensitive personal and financial information (e.g., health condition, name, and credit card number). Thus, trust in the platform and the healthcare provider is vital to ensure patients' willingness to provide such information and continue using the doctor's service (Guo et al. 2016). Second, due to the lack of physical examination and face-to-face interactions, patients may face the threat of reducing diagnostic accuracy. Hence, patients may need more trust to have a fair valuation of OMC and accept the service (Anderson and Agarwal 2011). Third, OMC is a type of private credence information goods (Dulleck and Kerschbamer 2006; Liu et al. 2016; Mou and Cohen 2017). Patients cannot easily observe the quality of OMC services even after consumption, making the assessment of OMC's value challenging. Thus, OMC experience, in which trust may play a vital role, becomes essential in payment decisions. In summary, we expect trust to play a vital role in $\mathrm{OMC}$ service continuance because of its close association with longterm relationship building and online consumers' willingness to pay (Kim 2014; Kim et al. 2009).

Although the viability of trust has been well researched in various online contexts (Guo et al. 2016; van Velsen et al. 2017), conflicting approaches regarding what constitutes online trust and how trust is measured have been presented. For example, there are two main research streams in the online trustrelated study: trust-in-technology (e.g., Akter et al. 2011; Meng et al. 2019a, 2019b), and trust-in-human (e.g., Deng et al. 2018; Guo et al. 2016). Both research streams frequently borrow the definition of trust from traditional interpersonal trust research (Benbasat and Wang 2005; Vance et al. 2008) and use measures such as integrity, competence, and benevolence. In the context of OMC, the concept of trust has been broadened to encompass all stakeholders such as the healthcare professional, the platform owner, and the technology (i.e., the digital platform architecture). Accordingly, the boundaries of the IT artifact and the social actors are becoming blurred, calling for a re-conceptualization of online trust to include interpersonal as well as technological aspects of trust in OMC. Thus, this research's primary objective is to re-examine the composition and explanatory role of trust in promoting patients' intention to continue the OMC service.

Our work contributes to the literature by integrating multiple streams of research to propose a multidimensional trust model and identify relevant factors in the context of the OMC service continuous. In the next sections, we review the online trust literature in various application domains. Based on the review, we summarize and compare the three popular trust models used in the relevant domains, such as online healthcare, online marketing, and information systems studies in Section 3. These models incorporate different conceptualization of trust (i.e., unitary vs. multidimensional) and explanatory mechanisms (i.e., trust as a direct cause vs. trust as a moderator). We categorize two sets of factors (i.e., risk and benefit) that contribute to trust-building in OMC based on the classic valence framework (Peter and Tarpey 1975) and ebusiness literature that focuses on online payment (Kim et al. 2009). They are (1) perceived validity and patientcenteredness that relate to OMC benefits, and (2) privacy risk and performance risk that relate to OMC risks. In Section 4, we use PLS path modeling to empirically validate the two commonly used trust mechanisms: (1) trust as a cause and (2) trust as a moderator. The former implies that trust gives rise to payment, while the latter suggests that trust is an "order qualifier" that buffers the impacts of OMC patients' riskbenefit evaluation. We perform data analysis and present the results in Section 5. We discuss the theoretical and practical implications, limitations, and future research directions before concluding the paper in Section 6.

\section{Conceptualization of Online Trust}

Online trust is a topic that has been researched in various problem domains, including online marketing, information systems, and online healthcare services. We conducted a systematic review on online trust in these areas, and the results are presented in Appendix A. At a high level, existing studies conceptualize online trust in four ways (Gefen et al. 2003; McKnight et al. 2002): (1) trust as a belief or collection of beliefs (Bhattacherjee 2002; Mcknight et al. 2011; Wang and Benbasat 2007; Kim et al. 2008); (2) trust as emotional feelings (Komiak and Benbasat 2006; Wang et al. 2016); (3) trust as an intention (Hoffmann et al. 2014); and (4) trust as a combination of these elements (McKnight and Chervany 2001; Gong et al. 2020). This study focuses on trusting beliefs (type 1), which are beliefs that a specific technology or service has the attributes necessary to perform as expected in a given situation where negative consequences are possible (Mcknight et al. 2011). 
Among the various trusting beliefs, this study focuses on both interpersonal and technological trust since OMC is a patient-provider interaction process on an IT platform (McKnight and Chervany 2001). Interpersonal trust reflects the social tie between trustor and trustee, which measures trust between people from three dimensions: competence, benevolence, and integrity (Mayer et al. 1995; McKnight et al. 2002). Technological trust, on the other hand, is channel-specific. It is a type of belief that structural conditions (e.g., the OMC platform architecture) are needed to ensure a successful outcome (McKnight et al. 2002; O'Connor and O'Reilly 2018). As a technological artifact, the OMC platform provides an institutional environment where rules and requirements are embedded to shape actors' interactions. The detailed definition of each trust dimension can be found in Table 1. In terms of when these trusting beliefs are developed, previous studies have highlighted the importance of history-bounded interactions that determine the perceived benefits and risks of interdependence, thus differentiating initial trust (Benbasat and Wang 2005) from the knowledge-based trust (Lippert 2007). Knowledge-based trust assumes socialization or courtship types of interaction, in which people try to learn from others and establish an interpersonal relationship. In this study, we focus on knowledge-based trust, in which patients should already have OMC service experience but need social interactions to establish an interpersonal relationship with the OMC providers before they would continue to pay for the services.

Although previous research on trust in online healthcare has well elucidated the essential role of trust in building doctor-patient relationships and deciding to continue the service, the multidimensional nature of trust has not yet been fully explored. Besides, despite the clear conceptual distinction between trust in humans and trust in technology, researchers often use human-like dimensions to study technological trust because people tend to anthropomorphize technology and ascribe them to human attributes (Benbasat and Wang 2005; Nowak and Rauh 2005; Vance et al. 2008).

This study proposes a comprehensive trust model for $\mathrm{OMC}$, which integrates interpersonal and technological trust - two knowledge-based trusting beliefs resulting from patientphysician interactions during OMC. This multidimensional trust construct incorporates physicians' quality (e.g., competence, integrity, and benevolence) and technological factors such as functionality, helpfulness, and reliability.

\section{Research Model Development}

\subsection{Theoretical Lens: The Valence Framework}

The proposed research models (see Fig. 1a-d) are based on the classic valence framework (Peter and Tarpey 1975), in which risk-benefit evaluation drives behavioral outcomes (Kim et al. 2009). The fundamental assumption is that perceived risk and perceived benefit simultaneously play a role in patients' decision-making process (Mou et al. 2016; Gao and Waechter 2017; Peter and Tarpey 1975). On the one hand, patients strive to minimize expected negative outcomes caused by paying for the continued OMC services. On the other hand, they are motivated to maximize potential benefits.

The valence framework is appropriate in our context because it provides a high-level cognitive rationale to incorporate both positive and negative aspects of OMC that may influence the decision to continue the service. It also allows us to incorporate context-specific factors that contribute to rational risk-benefit evaluation while considering the role of knowledge-based trust to reflect the OMC experience. Table 1 provides a summary of the constructs and their definitions.

\subsection{The Baseline Model}

We first specify patients' perceived benefits and risks of OMC to develop our baseline model. Since the physician provides the consultation service, not the technological infrastructure (i.e., the digital platform), patients expect to obtain personalized healthcare service from the physicians as their benefits. A good personalized online service should involve both outcome quality and process quality: the service outcome can fulfill the patients' needs and expectations, and patients are given individual attention during the process, which shows empathy (Collier and Bienstock 2006; Li and Suomi 2009). Hence, we propose perceived validity (adapted from Dai et al. 2011) and patient-centeredness (adapted from van Velsen et al. 2017) as two core mechanisms that measure patients' expected benefits of OMC. The former represents the outcome quality, and the latter represents the physicians' commitment to value patients' experience, which reflects process quality. The service quality and patients' feeling of being highly valued would help elicit patients' positive valuation of OMC (Mou and Cohen 2017), which in turn influences their intention to pay for the services continuously. Hence, we propose:

\section{H1. Perceived benefits of OMC, comprised of perceived va- lidity and patient-centeredness, has a positive impact on patients' OMC service continuance intention.}

On the other hand, the perceived risk of OMC is patients' perceptions of any uncertainties and negative consequences associated with OMC. Whereas various risk factors exist, in this study, we consider two predominant risk aspects - privacy risks and performance risks (Featherman and Pavlou 2003). During OMC, patients are often 
Table 1 Research constructs and their definitions

\begin{tabular}{|c|c|}
\hline Construct & Definition \\
\hline 1. Perceived benefits & $\begin{array}{l}\text { The extent to which using the OMC service helps achieve gains in obtaining } \\
\text { healthcare objectives (Kim et al. 2009). }\end{array}$ \\
\hline 2. Perceived validity & $\begin{array}{l}\text { The extent to which the physicians' services are helpful and responsive to } \\
\text { patients' inquiries (Dai et al. 2011). }\end{array}$ \\
\hline 3. Patient centeredness & $\begin{array}{l}\text { The extent to which the physicians' services are respectful of patients' } \\
\text { preferences and needs (van Velsen et al. 2017). }\end{array}$ \\
\hline 4. Perceived risks & $\begin{array}{l}\text { The extent to which using the OMC service exposes patients to negative } \\
\text { consequences (Featherman and Pavlou 2003). }\end{array}$ \\
\hline 5. Privacy risk & $\begin{array}{l}\text { The extent to which patients believe that using OMC leads to loss of control over } \\
\text { personal information without their knowledge or permission (Featherman and } \\
\text { Pavlou 2003). }\end{array}$ \\
\hline 6. Performance risk & $\begin{array}{l}\text { The extent to which patients believe that OMC may not perform as it was } \\
\text { designed and therefore failing to deliver the desired benefits (Featherman and } \\
\text { Pavlou 2003). }\end{array}$ \\
\hline 7. Interpersonal trust & $\begin{array}{l}\text { Patients' subjective belief that an online physician will fulfill its commitments } \\
\text { (Mayer et al. 1995). }\end{array}$ \\
\hline 8. Competence & $\begin{array}{l}\text { The belief that the physician has skills, abilities, and characteristics that enable } \\
\text { them to deliver the OMC services (Mayer et al. 1995). }\end{array}$ \\
\hline 9. Benevolence & $\begin{array}{l}\text { The belief that the physician wants to do good to the patient, aside from an } \\
\text { egocentric profit motive (Mayer et al. 1995). }\end{array}$ \\
\hline 10. Integrity & $\begin{array}{l}\text { The belief that a physician adheres to a set of principles that the patient finds } \\
\text { acceptable (Mayer et al. 1995). }\end{array}$ \\
\hline 11. Technological trust & $\begin{array}{l}\text { Patients' subjective belief that the technological infrastructures supporting OMC } \\
\text { is dependable (Mcknight et al. 2011). }\end{array}$ \\
\hline 12. Functionality & $\begin{array}{l}\text { The belief that the technological infrastructures supporting OMC have the } \\
\text { capabilities, functions, or features to accomplish what needs to be done } \\
\text { (Mcknight et al. 2011). }\end{array}$ \\
\hline 13. Reliability & $\begin{array}{l}\text { The belief that technological infrastructures supporting OMC will consistently } \\
\text { operate properly (Mcknight et al. 2011). }\end{array}$ \\
\hline 14. Helpfulness & $\begin{array}{l}\text { The belief that the technological infrastructures supporting OMC will provide } \\
\text { adequate and responsive help for users (Mcknight et al. 2011). }\end{array}$ \\
\hline 15. Trust in $\mathrm{OMC}$ & $\begin{array}{l}\text { Patients' subjective belief that the OMC platform (as an organization) will } \\
\text { enforce fair rules, procedures, and outcomes (Bansal et al. 2016; van Velsen } \\
\text { et al. 2017) }\end{array}$ \\
\hline $\begin{array}{l}\text { 16. OMC service } \\
\text { continuance intention }\end{array}$ & The extent to which the patient plans to continue the OMC services in the future. \\
\hline
\end{tabular}

requested to provide a great deal of detailed personal information. While OMC platforms take advantage of personal information to provide personalized services, patients often view this as an invasion of privacy (Guo et al. 2016). Two types of privacy risk arise from the platforms' inability or unwillingness to effectively manage the patients' personal information: (1) the improper use of information due to the absence of appropriate controls, and (2) the secondary use of personal information without the patient's consent (Gao et al. 2015). Although many platforms have established information protection regulations, and many countries have made privacy-related laws in recent years, data breaches and inappropriate data use are still major concerns for online privacy (Anderson and
Agarwal 2011; Bansal et al. 2015; Bansal et al. 2016). Even if the OMC platform strictly follows the regulations, these risks cannot be entirely avoided. In addition, in OMC, the platform is not the only data owner, and the doctors' careless in data treatment may also cause privacy invasion. However, it is difficult for the platform to manage each doctors' data usage activities. Thus, we consider privacy risks a salient inhibitor of a range of online behaviors, especially in the payment process (Chen et al. 2018; Gao et al. 2015; Mousavi et al. 2020).

Similarly, the risk perception may come from the platform's malfunctioning or the physicians' underperformance (i.e., performance risk). For example, although patients may applaud the convenience of online 

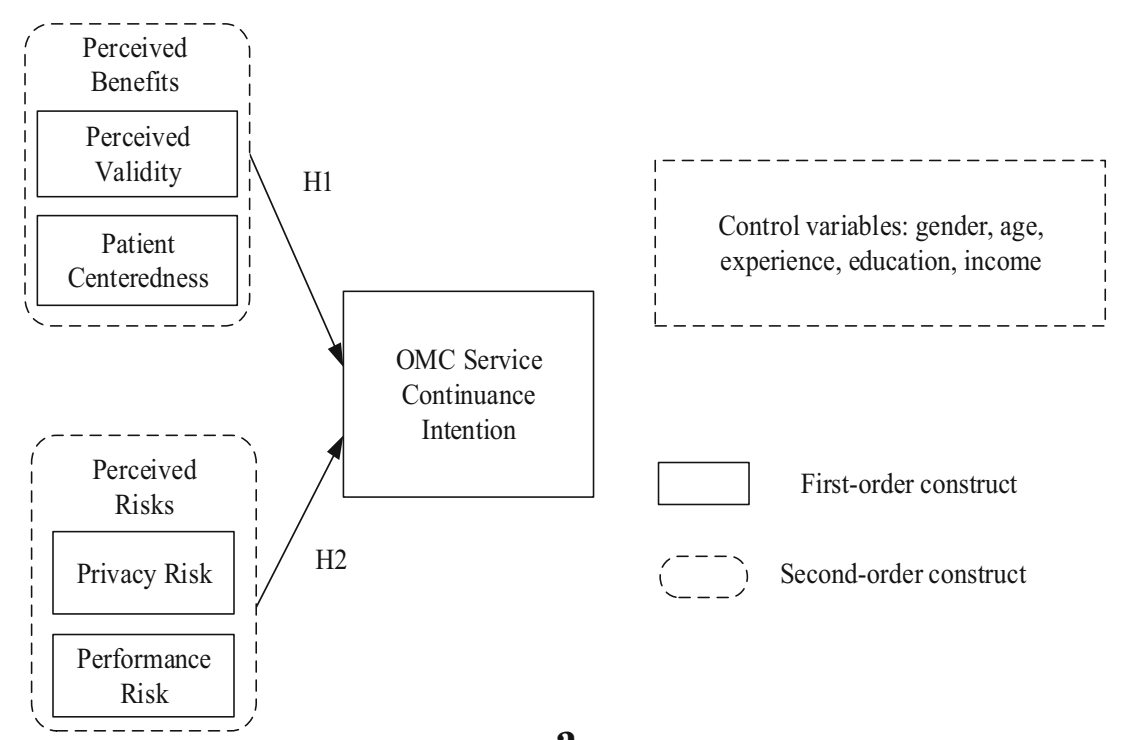

a

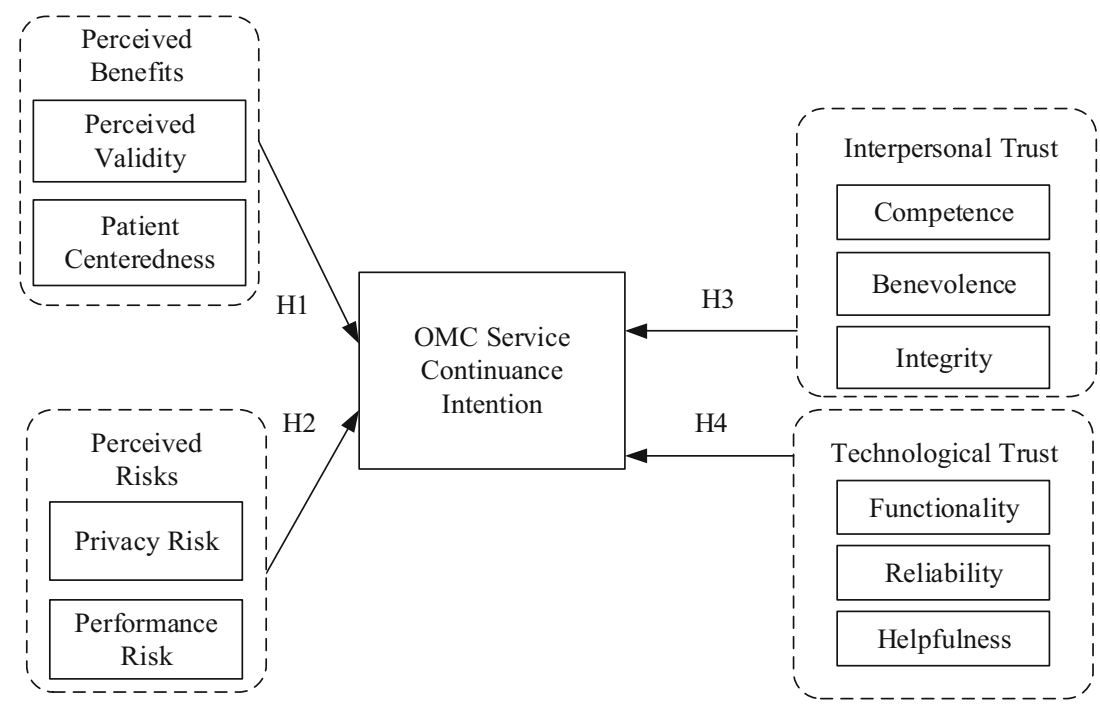

First-order construct

, Second-order construct
First-order construct

(--- Second-order construct
Control variables: gender, age,

experience, education, income 


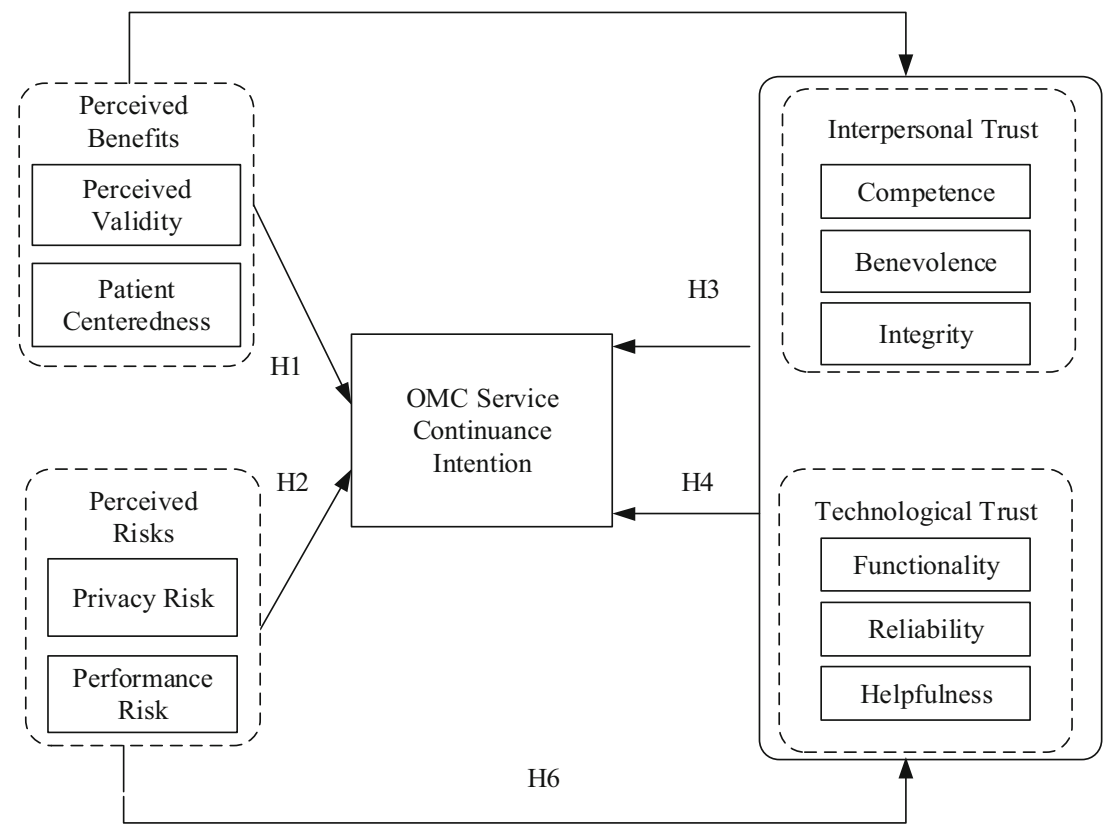

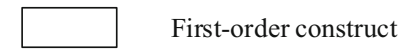

(-- Second-order construct

Third-order construct

Control variables: gender, age, experience, education, income

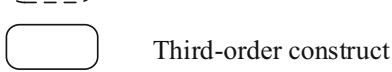

c
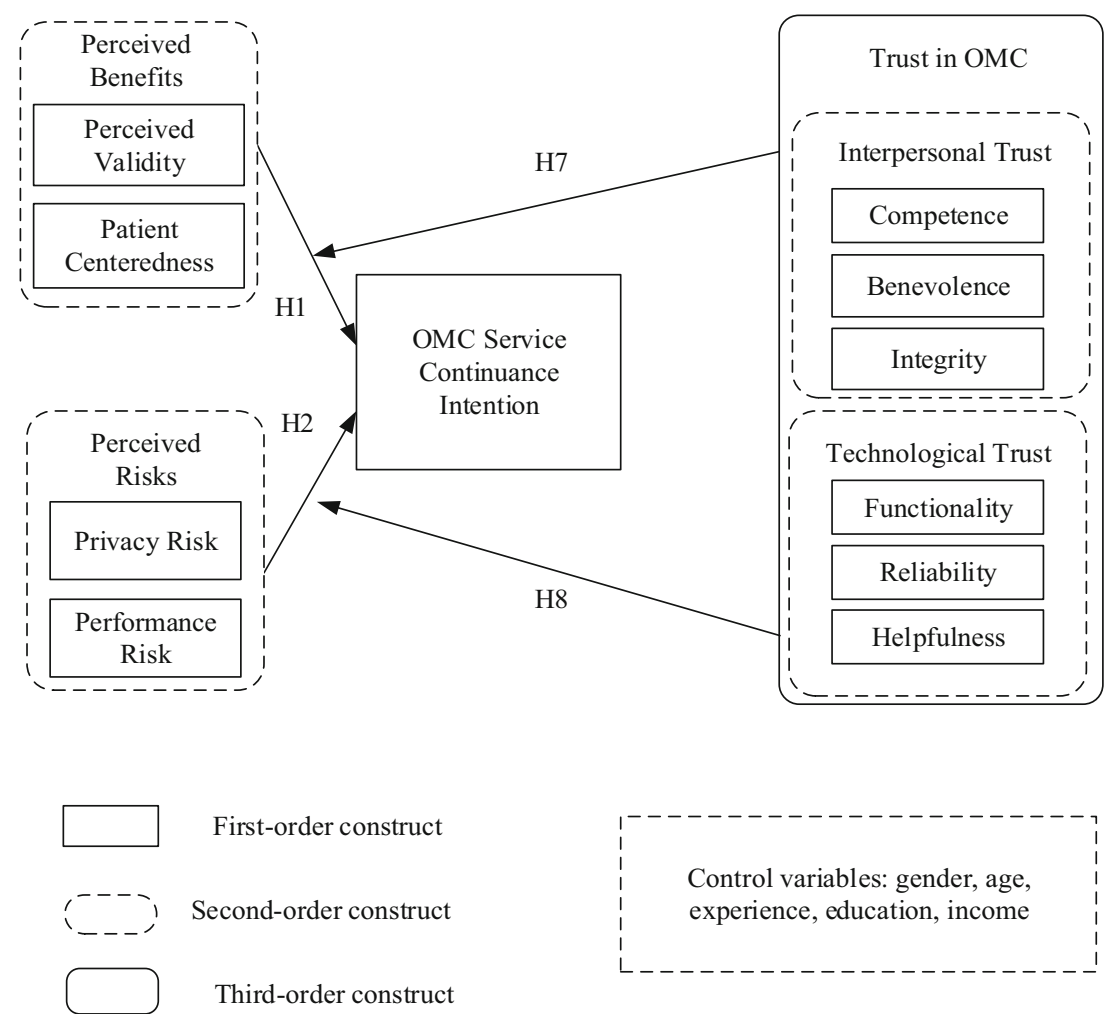

Control variables: gender, age, experience, education, income

Fig. 1 continued. 


\subsection{Pay because I Trust: Trust as a Direct Cause}

In addition to the risk and benefit factors mentioned above, trust has been proposed as an additional driving factor that directly influences online purchase (Kim 2014). This is because under uncertain situations, like our OMC context, trust has been found to promote risk-taking behavior and service satisfaction (Mayer et al. 1995; McKnight et al. 2002; Fang et al. 2014; Mohr and Walter 2019). Previous studies mainly draw on two theories to explain the relationship between trust and service continuance - the expectation-confirmation theory and the social exchange theory (Kim 2014; Pavlou et al. 2007; Ye and Kankanhalli 2017). Bhattacherjee (2001) and Oliver and Burke (1999) described the logic of the expectation-confirmation theory: consumers first form an initial expectation of a specific product or service before the transaction. After their initial consumption, they form perceptions about its performance. Then, consumers compare their performance perceptions with their original expectations and determine the extent to which their expectations are confirmed. Finally, they develop a level of satisfaction. Trust contributes to expectation formation and thus influences their satisfaction and intention to continue the service.

Social exchange theory posits that individuals behave in ways to maximize benefits and minimize costs during the exchange. An important tenet of the theory is that a trustortrustee relationship terminates or continues based on the results of two types of comparisons (Kim 2014): Alternative relationship and the give-and-take comparisons. Consumers take part in the exchange only when they expect rewards to exceed the costs that may incur (Gefen and Ridings 2002). As an indicator of how well the OMC platforms provide services, trust is critical because if patients trust the platform, both parties will build a mutual understanding, and the relationship will be more likely to continue (Mpinganjira 2018). Therefore, as OMC patients increase trust, they are more likely to continue the relationship with the doctor and pay for the service continuously. Thus, we propose:

H3. Interpersonal trust, consisting of competence, benevolence, and integrity, positively impacts patients' OMC service continuance intention.

H4. Technological trust, consisting of functionality, reliability, and helpfulness, positively impacts patients' OMC service continuance intention.

\subsection{The Mediating Role of Trust}

Although previous studies have suggested that trust influences online purchase and payment, it is unclear whether trust is a direct or indirect cause when other evaluation mechanisms are present simultaneously. In this study, we propose that although perceived benefits and perceived risks are important attributes that affect the net valence (as proposed in $\mathrm{H} 1$ and $\mathrm{H} 2$ ), trust mediates the impacts of risk-benefit evaluation. That is, the physician's performance and patient-centeredness, as well as the privacy and performance risks, will impact the patient's level of trust towards the OMC services, which subsequently influences the service continuance intention (Guo et al. 2016). Hence, we propose:

H5. Trust in OMC, consisting of interpersonal and technological trust, mediates the positive relationship between perceived benefits and patients' OMC service continuance intention.

H6. Trust in OMC, consisting of interpersonal and technological trust, mediates the negative relationship between perceived risks and patients' OMC service continuance intention.

\subsection{Pay for a Trusting Service: Trust as a Moderator}

Besides modeling trust as a direct cause, a handful of studies argued that trust should be a moderator (Chung and Kwon 2009). As suggested by Doney and Cannon (1997), trust appears "to operate as an 'order qualifier', not an 'order winner"' (p. 47). From this perspective, trust does not directly elicit particular behavior outcomes but influences how people interpret or evaluate information related to their attitude and behavior (Jarvenpaa et al. 2004). For example, previous studies in e-commerce have found that trust affects how the website's past use experience is assessed, which impacts its continued use (Bansal et al. 2016; Venkatesh et al. 2016). In a highly uncertain environment such as $\mathrm{OMC}$, if patients have trust in a particular provider or the OMC platform, they may have higher tolerance of the potential vulnerability of that OMC (Bonoma 1976; Mcknight et al. 2011). As a result, they may develop stronger intentions to use OMC even at the same level of perceived benefits and perceived risks (Agarwal and Prasad 1998). By contrast, patients with less trust will be less likely to expose themselves to uncertainty and risks. For example, although patients may agree that a physician provides valid and patientcentered recommendations, their concerns over the potential privacy risks are magnified due to the lack of trust in that OMC. Hence, we propose two alternative hypotheses:

H7. Trust moderates the positive relationship between perceived benefits and patients' OMC service continuance intention.

H8. Trust moderates the negative relationship between perceived risks and patients' OMC service continuance intention. 


\section{Research Method}

\subsection{Research Context and Data Collection}

We conduct an online survey to test the hypotheses. We initially sent out 2000 questionnaires to the users of one of the largest OMC platforms in China. Participation in our survey was voluntary and anonymous, and a cash prize was awarded to the participants that have completed all survey questions. A total of 586 questionnaires were collected within a month. After eliminating invalid responses, including participants with limited use of OMC and those who appear to provide random answers, 365 valid responses were included for analysis. Respondents' demographic statistics are presented in Table 2.

\subsection{Construct Measures}

The constructs in our model have been studied in the extant ecommerce literature. Hence, we adapt the existing measurements, which are shown in Appendix B. Each construct is

Table 2 Demographic statistics of the respondents

\begin{tabular}{|c|c|c|c|}
\hline Demographic & Category & Frequency & Percentage \\
\hline \multirow[t]{5}{*}{ Age (years) } & Under 18 & 0 & $0 \%$ \\
\hline & $18 \sim 30$ & 173 & $47 \%$ \\
\hline & $31 \sim 40$ & 146 & $40 \%$ \\
\hline & $41 \sim 50$ & 40 & $11 \%$ \\
\hline & over 50 & 6 & $2 \%$ \\
\hline \multirow[t]{2}{*}{ Gender } & Female & 196 & $54 \%$ \\
\hline & Male & 169 & $46 \%$ \\
\hline \multirow[t]{3}{*}{ Education } & High school or lower & 16 & $4 \%$ \\
\hline & College or undergraduate & 302 & $83 \%$ \\
\hline & graduate & 47 & $13 \%$ \\
\hline \multirow[t]{4}{*}{ Monthly income } & Less than $¥ 8000$ & 155 & $43 \%$ \\
\hline & $¥ 8001 \sim 15,000$ & 158 & $43 \%$ \\
\hline & $¥ 15,001 \sim 20,000$ & 31 & $9 \%$ \\
\hline & $¥$ more than 20,000 & 21 & $6 \%$ \\
\hline \multirow[t]{4}{*}{ Use experience } & Less than 6 months & 57 & $16 \%$ \\
\hline & 6 months $\sim 1$ year & 129 & $35 \%$ \\
\hline & $1 \sim 2$ years & 115 & $32 \%$ \\
\hline & More than 2 years & 64 & $18 \%$ \\
\hline \multirow[t]{5}{*}{ Use frequency } & Irregularly & 162 & $44 \%$ \\
\hline & Seldom & 9 & $3 \%$ \\
\hline & Occasionally & 68 & $19 \%$ \\
\hline & Often & 116 & $32 \%$ \\
\hline & Always & 10 & $3 \%$ \\
\hline
\end{tabular}

measured by at least three indicators to provide a more accurate representation (Wynne W. Chin 1998). Previous literature suggests that an individual's age, gender, levels of education, income, and use experience can influence their online purchase behavior (Pavlou and Fygenson 2006). Hence, we also include them in the models as control variables. The original questionnaire was in Chinese, and we conducted a backtranslation procedure to ensure the validity of the translation.

\section{Analysis and Results}

Partial Least Squares (PLS) regression is used to test the measurement and the structural models. PLS has been extensively used in the IS and healthcare research because of its capability to handle the highly complex predictive models with formative constructs (Bhattacherjee and Premkumar 2004). Comparing with the covariance-based structural equation modeling, PLS is appropriate for this study because: (1) our model is theory-driven, yet the inclusion of a formative second-order construct makes it impossible to meet the identification requirement for covariance-based approach even with a large sample size; and (2) we seek to understand the variations in the outcome as maximally explained by the proposed antecedents, rather than how well the model fits the sample dataset to make predictions (i.e., goodness-of-fit logic for covariance-based approach).

We model trust in OMC as a third-order reflective construct using the mimic approach (Diamantopoulos 2011), and the second-order interpersonal trust and technological trust are modeled as formative constructs. As explained in the background section, patients often form a general trust belief that depicts different aspects of trust - interpersonal versus technological in our study. At the lower level, patients' perception of whether an OMC service is trustworthy depends on their experience and judgments on OMC's benevolence, competence, integrity, functionality, reliability, and helpfulness. Thus, these six first-level dimensions build higherlevel interpersonal and technological trust.

All first-level trust dimensions are reflectively measured following previous studies (Guo et al. 2016; Lankton et al. 2015) based on measurement theory and the causal direction between the measures and the constructs (Diamantopoulos and Siguaw 2006). Perceived benefits and perceived risks are second-order constructs that are reflectively measured.

\subsection{Testing the Measurement Model}

We conduct a formal exploratory factor analysis to detect each latent construct's reliability and validity (see Tables 3 and 4). 
Table 3 Descriptive statistics and reliability coefficients for the constructs

\begin{tabular}{llllll}
\hline Constructs & $M$ & $S D$ & Alpha & CR & AVE \\
\hline 1. Perceived Benefits (PB) & 5.88 & 0.87 & 0.783 & 0.866 & 0.684 \\
2. Perceived Validity (PV) & 5.87 & 0.88 & 0.778 & 0.859 & 0.670 \\
3. Patient Centeredness (PC) & 5.57 & 1.17 & 0.763 & 0.861 & 0.673 \\
4. Perceived Risk (PR) & 3.27 & 1.44 & 0.829 & 0.884 & 0.657 \\
5. Performance Risk (Per) & 3.10 & 1.34 & 0.720 & 0.885 & 0.806 \\
6. Privacy risk (Pri) & 3.49 & 1.59 & 0.792 & 0.920 & 0.869 \\
7. Functionality (Fun) & 5.75 & 0.97 & 0.712 & 0.828 & 0.616 \\
8. Reliability (Re) & 4.91 & 1.33 & 0.716 & 0.836 & 0.629 \\
9. Helpfulness (He) & 5.70 & 1.04 & 0.709 & 0.811 & 0.589 \\
10. Competence (C) & 5.73 & 1.10 & 0.708 & 0.795 & 0.564 \\
11. Benevolence (B) & 5.52 & 1.15 & 0.715 & 0.836 & 0.629 \\
12. Integrity (I) & 5.65 & 1.09 & 0.789 & 0.876 & 0.703 \\
13. Trust in OMC (TO) & 5.69 & 0.94 & 0.805 & 0.911 & 0.837 \\
14. Continuance Intention (CI) & 5.56 & 1.13 & 0.812 & 0.914 & 0.841 \\
\hline
\end{tabular}

All constructs' reliability measurements of the Cronbach's alpha and the Fornell's composite score are higher than the threshold benchmark of 0.7 (Nunnally and Bernstein 1994;
Fornell and Larcker 1981), indicating an adequate level of internal consistency.

As shown in Appendix C, the constructs appear to have acceptable convergent validity because all item loadings are greater than 0.50 , and the items for each construct load on only one factor with an eigenvalue greater than 1.0 (Wixom and Watson 2001). Besides, as shown in Table 4, all constructs have an Average Variance Extracted (AVE) of at least 0.5, and the squared roots of the AVE of each latent construct are higher than the highest correlation with any other latent construct (Fornell and Larcker 1981), indicating that discriminant validity is established (Chin 1998). In addition, all Variance Inflation Factors (VIFs) are lower than 3.33 (Cenfetelli and Bassellier 2009; Diamantopoulos and Siguaw 2006), indicating that multicollinearity does not exist in the model.

\subsection{Common Method Bias}

We follow Podsakoff et al.'s (2003) recommendations and use Harmon's single factor test (Podsakoff and Organ 1986) to detect potential common method bias. Since the first un-rotated factor explains only $27.3 \%$ of

Table 4 Correlations of the latent variables

\begin{tabular}{|c|c|c|c|c|c|c|c|c|c|c|c|c|c|c|c|c|}
\hline Variable & 1 & 2 & 3 & 4 & 5 & 6 & 7 & 8 & 9 & 10 & 11 & 12 & 13 & 14 & 15 & 16 \\
\hline 1. $\mathrm{PB}$ & 0.827 & & & & & & & & & & & & & & & \\
\hline 2. PV & 0.477 & 0.819 & & & & & & & & & & & & & & \\
\hline 3. $\mathrm{PC}$ & 0.432 & 0.585 & 0.821 & & & & & & & & & & & & & \\
\hline 4. $P R$ & -0.325 & -0.300 & -0.321 & 0.811 & & & & & & & & & & & & \\
\hline 5. Per & -0.354 & -0.397 & -0.332 & 0.678 & 0.848 & & & & & & & & & & & \\
\hline 6. Pri & -0.300 & -0.248 & -0.288 & 0.581 & 0.643 & 0.890 & & & & & & & & & & \\
\hline 7. Fun & 0.509 & 0.541 & 0.417 & -0.280 & -0.384 & -0.239 & 0.785 & & & & & & & & & \\
\hline 8. $\operatorname{Re}$ & 0.396 & 0.446 & 0.454 & -0.371 & -0.398 & -0.315 & 0.520 & 0.793 & & & & & & & & \\
\hline 9. $\mathrm{He}$ & 0.501 & 0.584 & 0.552 & -0.304 & -0.401 & -0.275 & 0.642 & 0.582 & 0.767 & & & & & & & \\
\hline 10. $\mathrm{C}$ & 0.472 & 0.469 & 0.496 & -0.357 & -0.414 & -0.364 & 0.520 & 0.493 & 0.590 & 0.751 & & & & & & \\
\hline 11. B & 0.428 & 0.442 & 0.537 & -0.372 & -0.401 & -0.416 & 0.401 & 0.484 & 0.493 & 0.594 & 0.793 & & & & & \\
\hline 12. I & 0.434 & 0.449 & 0.547 & -0.400 & -0.448 & -0.438 & 0.423 & 0.514 & 0.557 & 0.606 & 0.609 & 0.838 & & & & \\
\hline 13. PT & 0.603 & 0.521 & 0.520 & -0.483 & -0.515 & -0.375 & 0.463 & 0.417 & 0.501 & 0.532 & 0.511 & 0.528 & 0.915 & & & \\
\hline 14. CI & 0.590 & 0.463 & 0.440 & -0.436 & -0.436 & -0.315 & 0.384 & 0.399 & 0.413 & 0.449 & 0.354 & 0.355 & 0.603 & 0.917 & & \\
\hline 15. $\mathrm{TT}^{a}$ & 0.552 & 0.617 & 0.559 & -0.375 & -0.465 & -0.326 & 0.848 & 0.825 & 0.874 & 0.630 & 0.542 & 0.587 & 0.563 & 0.470 & - & \\
\hline 16. $\mathrm{IT}^{b}$ & 0.516 & 0.528 & 0.615 & -0.440 & -0.492 & -0.476 & 0.518 & 0.580 & 0.636 & 0.837 & 0.853 & 0.881 & 0.682 & 0.446 & 0.682 & - \\
\hline
\end{tabular}

Notes: The diagonal values () represent the square root of the Average Variance Extracted (AVE). Off diagonal values represent latent variable correlations

${ }^{a}$ Technological Trust (second order); ${ }^{b}$ Interpersonal Trust (second order) 
the covariance of the main constructs in our model, we conclude that there is no substantial amount of common method bias present in our model.

We also use a modified marker variable analysis to further test the common method bias. Following Rönkkö and Ylitalo (2011), we use Internet Technicality (measured by three items) as our marker variable and perform regression analysis on four latent constructs. The results show that the marker variable has low correlations with items in our research model and has no significant impact on service continuous intention, perceived benefits, perceived risks, and trust. The hypothesized relationships are qualitatively equal to the results before the marker variable was incorporated, indicating that common method bias has little impact.

\subsection{Testing the Structural Models}

Following the construct-level analysis, we use PLS to obtain the second-order formative factors (i.e., interpersonal trust and technological trust) (Diamantopoulos et al. 2008) and the estimated structural model. The $T$-tests of the path coefficients are used to compare the models and draw conclusions for our hypotheses. Table 5 describes the five models.

\subsubsection{Assessment of Trust as a Direct Cause}

As shown in Table 6, all four models show a strong positive effect between a patient's perceived benefits and service continuous intention (e.g., the baseline model, $\beta=$ $0.464, p<0.01)$. In contrast, a patient's perceived risks show a strong negative effect (e.g., the baseline model, $\beta=-0.218, p<0.01)$. Hence, hypotheses 1 and 2 are supported. Table 6 also shows that the perceived benefits and perceived risk account for $45.3 \%$ of the variance in the baseline model's service continuance intention.

For the multidimensional trust model (Model 1.1), both interpersonal trust $(\beta=0.513, p<0.01)$ and technological trust $(\beta=0.559, p<0.01)$ show strong positive effects on the patient's service continuance intention. Hence, hypotheses 3 and 4 are supported. Moreover, when trust in OMC is introduced as a third-order construct (Model 1.2) to encompass both interpersonal and technological trust, the explanatory power increases to $50.5 \%$. We also examine the explanatory power of the unitary trust model (Model 1.3), which is a commonly used approach in previous research. As indicated in Table 6, the multidimensional trust possesses more explanatory power than the unitary trust in terms of $R^{2}$. In summary, the inclusion of the third-order trust construct - trust in OMC (see model 1.2) results in a superior model with a beta of 0.318 at $p<.001$ significance, an increase in the $R^{2}$ for service continuance intention ( $\Delta R^{2}$ against the base is 0.105$)$, and medium effect size. ${ }^{2}$ For the control variables, there are considerable variations among different use experience and use frequency groups, suggesting that service preferences vary along with the OMC service experience and other individual characteristics.

\subsubsection{Assessment of Trust as a Mediator}

Since interpersonal trust and technological trust tackle different aspects of OMC, we conduct a multiple mediation analysis (Preacher and Hayes 2008) that investigates: 1) the total indirect effect, and (2) the specific indirect effect associated with each putative mediator. We have applied the bootstrapping method to assess the Confidence Interval (CI) of the total and the specific indirect effects. As shown in Fig. 2, all paths are significant. Tables 7 and 8 provide the mediation effects (path $a^{*} b$ ) of perceived benefit and perceived risks, respectively, on service continuance intention of OMC. Tables 7 and 8 also show the indirect effects and the Bootstrapping 95\% CI of the total and the two mediation effects. The results in Table 7 show that the true total indirect effect is estimated at 0.333 , with the BiasCorrected 95\% CI ranges from 0.074 to 0.208 . Since the $95 \%$ CI does not include zero, we conclude that the total indirect effect is significant (Baron and Kenny 1986). Similarly, the other two mediation effects, technological trust and interpersonal trust, also do not have zero included in their corresponding 95\% CIs; therefore, both are considered significant.

Finally, we compare the strength of the individual indirect effects on one another. Since the 95\% CI includes zero, there is no significant difference in the mediating effect between interpersonal trust and technological trust. These results indicate that the effects of perceived benefits on service continuance intention are mediated through interpersonal trust and technological trust, thus supporting H5. Similar results for perceived risks can be found in Table 8 , indicating that the effects of perceived risks are mediated through both interpersonal and technological trust, thus supporting H6.

\subsubsection{Assessment of Trust as a Moderator}

We follow the PLS product-indicator approach (Chin et al. 2003) to perform the moderator analysis and present the results in Fig. 3a \& b. Trust in OMC is modeled as a composite

\footnotetext{
${ }^{2}$ The difference in $R^{2}$ is used to assess the overall effect size $f^{2}$ for the interaction where $.02,0.15$, and 0.35 have been suggested to be considered as small, moderate, and large effects, respectively (Cohen 1988).
} 
Table 5 Model comparison

\begin{tabular}{|c|c|c|}
\hline Models & Role of Trust & Dimensionality of Trust \\
\hline Baseline & No trust & N/A \\
\hline Model 1.1 & Direct cause & $\begin{array}{l}\text { Multifaceted trust (formative second-order } \\
\text { interpersonal trust + formative second-order } \\
\text { technological trust) }\end{array}$ \\
\hline Model 1.2 & Direct cause & $\begin{array}{l}\text { Trust as a third-order reflective construct } \\
\text { consisting of second-order interpersonal } \\
\text { and technological trust }\end{array}$ \\
\hline Model 1.3 & Direct cause & Unitary trust (reflective) \\
\hline Model 2 & Indirect cause (Mediator) & $\begin{array}{l}\text { Trust as a third-order reflective construct } \\
\text { consisting of second-order interpersonal } \\
\text { and technological trust }\end{array}$ \\
\hline Model 3 & Moderator & $\begin{array}{l}\text { Trust as a third-order reflective construct consisting of } \\
\text { second-order interpersonal and technological trust }\end{array}$ \\
\hline
\end{tabular}

Table 6 Hierarchical Regression Analysis Predicting Service Continuance Intentions (Trust as a Direct Cause on Three Alternative Models $1.1 \sim 1.3$ )

\begin{tabular}{|c|c|c|c|c|}
\hline Variables & Baseline & Model 1.1 & Model 1.2 & Model 1.3 \\
\hline \multicolumn{5}{|l|}{ Control variables } \\
\hline Age & -0.009 & 0.052 & 0.052 & -0.009 \\
\hline Gender & 0.018 & 0.056 & 0.057 & 0.016 \\
\hline Education & 0.048 & 0.039 & 0.039 & 0.058 \\
\hline Income & 0.061 & 0.053 & 0.053 & $0.077^{* *}$ \\
\hline Use experience & $0.094^{* * *}$ & $0.114^{* *}$ & $0.116^{* *}$ & $0.102^{* *}$ \\
\hline Use frequency & $0.118^{* * *}$ & $0.139^{* * *}$ & $0.140^{* * *}$ & $0.085^{* *}$ \\
\hline General perception & 0.002 & 0.037 & 0.036 & -0.049 \\
\hline Perceived benefits & $0.464^{* * * *}$ & $0.434^{* * * *}$ & $0.418^{* * * *}$ & $0.333^{* * * *}$ \\
\hline Perceived validity & $0.341^{* * *}$ & $0.341^{* * *}$ & $0.341^{* * * *}$ & $0.341^{* * * *}$ \\
\hline Patient centeredness & $0.232^{* * *}$ & $0.232^{* * * *}$ & $0.232^{* * * *}$ & $0.232^{* * * *}$ \\
\hline Perceived risks & $-0.218^{* * * *}$ & $-0.188^{* * * *}$ & $-0.171^{* * * * *}$ & $-0.126^{* * * *}$ \\
\hline Privacy risk & $0.248^{* * *}$ & $0.248^{* * * *}$ & $0.248^{* * * *}$ & $0.248^{* * *}$ \\
\hline Performance risk & $0.518^{* * *}$ & $0.518^{* * * *}$ & $0.518^{* * * *}$ & $0.518^{* * *}$ \\
\hline Technological trust & & $0.513^{* *}$ & & \\
\hline Reliability & & $0.443^{* * * *}$ & & \\
\hline Functionality & & $0.314^{* * * *}$ & & \\
\hline Helpfulness & & $0.417^{* * *}$ & & \\
\hline Interpersonal trust & & $0.559^{* *}$ & & \\
\hline Competence & & $0.349^{* * * *}$ & & \\
\hline Benevolence & & $0.381^{* * * *}$ & & \\
\hline Integrity & & $0.434^{* * * * *}$ & & \\
\hline Trust in OMC & & & $0.318^{* * * *}$ & $0.150^{* *}$ \\
\hline$R^{2}$ & 0.453 & 0.463 & 0.505 & 0.463 \\
\hline Adjusted $R^{2}$ & & 0.007 & 0.052 & 0.010 \\
\hline$\Delta R^{2}$ against base & & 0.013 & 0.105 & 0.019 \\
\hline Effect size $^{a}$ & & small & medium & small \\
\hline
\end{tabular}

${ }^{*} p<0.05 ;{ }^{* *} p<0.01 ;{ }^{* * *} p<0.001$

Note. ${ }^{a}$ The difference in $R^{2}$ is used to assess the overall effect size $f^{2}$ for the interaction where $.02,0.15$, and 0.35 have been suggested to be considered as small, moderate, and large effects, respectively (Cohen 1988) moderator that includes both technological and interpersonal facets because both types of trusts should holistically play a buffering role.

We estimate the influence of perceived benefits (path $c$ ), the direct impact of trust (path $b$ ), and the influence of the interaction term (i.e., perceived benefits*trust in the platform) on service continuance intention (path $d$ in Fig. 3a). The results show a standardized path coefficient of 0.060 for the synergistic effect (path $d$ ), which is not significant at $p<0.05$. Similarly, the synergistic effect between perceived risks and trust is also not significant (path $d^{\prime}$ ' in Fig. $3 b)$. Thus, the moderator propositions (H7 and H8) are not supported. We summarize all the hypotheses and findings in Appendix D.

\subsection{Post-hoc Analysis}

Although we developed our model from the wellestablished valence framework and trust literature, endogeneity issues may still arise due to omitted variables and reverse causality in PLS modeling (BenítezAmado et al. 2016). Since our dependent variable (i.e., service continuance intention) is future-oriented, reverse causality is of less concern in our model. Following the guideline provided by Hult et al. (2018), we conducted the Gaussian copular analysis to detect the potential endogeneity issue caused by omitted variables. The procedure and results are presented in Appendix E. In Gaussian copular analysis, the copula is computed from the inverse of the Gaussian normal cumulative distribution function. The regression models are then estimated by incorporating the copula as an additional independent variable that controls the correlation between the error term and the endogenous constructs in the regression model. Our results show that no Gaussian copula is 
Table 7 Mediation Effect of Perceived Benefits on Service Continuance Intention through Interpersonal Trust and Technological Trust

\begin{tabular}{lllll}
\hline Mediator & Indirect effect (SD) & \multicolumn{2}{l}{ BC 95\% CI } & \multirow{2}{*}{ Relative Mediation effect } \\
\cline { 3 - 4 } & & \multicolumn{2}{l}{ LL } & UL \\
& & 0.025 & 0.163 & $22.742 \%$ \\
\hline Technological trust (1) & $0.141(0.039)$ & 0.052 & 0.159 & $30.967 \%$ \\
Interpersonal trust (2) & $0.192(0.041)$ & 0.074 & 0.208 & $53.710 \%$ \\
Total effect of (1) \& (2) & $0.333(0.044)$ & -0.138 & 0.106 & - \\
(1) vs. (2) & $-0.051(0.069)$ & & \\
\hline
\end{tabular}

Note. $\mathrm{BC}=$ bias corrected $\mathrm{CI}=$ confidence interval; $L L=$ lower limit; $U L=$ upper limit significant, thus ruling out the problem of endogeneity caused by omitted variables in our research model.

\section{Discussion}

We seek to examine the constitution of online trust and the two plausible explanations regarding how trust contributes to the service continuance decisions in OMC (i.e., trust as a cause vs. trust as a moderator). Our results show that the multidimensional conceptualization of trust is superior to the unitary conceptualization. The proposed model highlights the importance of enhancing the social ties between patients and physicians (i.e., interpersonal trust) and the technological capabilities of the system (i.e., technological trust) when promoting OMC. The significant multiple mediation effects of interpersonal trust and technological trust also confirmed our propositions. However, the "trust as a moderator" proposition was not confirmed.

\subsection{Theoretical Implications}

Our study contributes to both trust and online healthcare service literature in several ways. First, we propose an integrated model of patients' service continuance decision in OMC, which includes both the interpersonal and the technological aspects of the trust mechanisms. Since performance risk and privacy risk are major barriers to establish trust and service continuance intention, OMC platforms need to help patients resolve their concerns regarding OMC service procedures (e.g., data management) and outcomes (e.g., treatment effectiveness). We have also identified two sets of perceived benefits (i.e., perceived validity and patient-centeredness) relevant to establishing interpersonal and technological trust, which play mediating roles in affecting the relationships between perceived benefits and risks and patients' OMC service continuance intention.

Second, although prior research has examined some of our identified factors (e.g., perceived benefits and perceived risks), they primarily focused on their direct effects on unidimensional trust. By contrast, our study aims to clarify the type of trust (interpersonal vs. technological) and the inner causality between the measurements and the constructs (i.e., formative vs. reflective), which provides a comprehensive understanding of the trust-based consumer decision-making in online healthcare services. In addition, the multidimensional conception of trust allows us to implement a multiple mediation model, which sheds light on how interpersonal versus technological trust mechanisms may synergistically reduce patients' perceived risks and reinforce patients' perceived benefits, therefore
Table 8 Mediation of the Effect of Perceived Risks on Service Continuance Intention through Interpersonal Trust and Technological Trust

\begin{tabular}{lllll}
\hline Mediator & Indirect effect $(S D)$ & \multicolumn{2}{l}{ BC 95\% CI } & \multirow{2}{*}{ Relative Mediation effect } \\
\cline { 3 - 4 } & & \multicolumn{2}{l}{ LL } & \multicolumn{2}{c}{$U L$} \\
\hline Technological trust (1) & $-0.092(0.035)$ & -0.206 & -0.083 & $28.482 \%$ \\
Interpersonal trust (2) & $-0.074(0.043)$ & -0.122 & -0.001 & $22.910 \%$ \\
Total effect of (1) \& (2) & $-0.166(0.032)$ & -0.231 & -0.111 & $51.393 \%$ \\
(1) vs. (2) & $0.018(0.052)$ & -0.138 & 0.106 & - \\
\hline
\end{tabular}

Note. $\mathrm{BC}=$ bias corrected; $\mathrm{CI}=$ confidence interval; $L L=$ lower limit; $U L=$ upper limit 

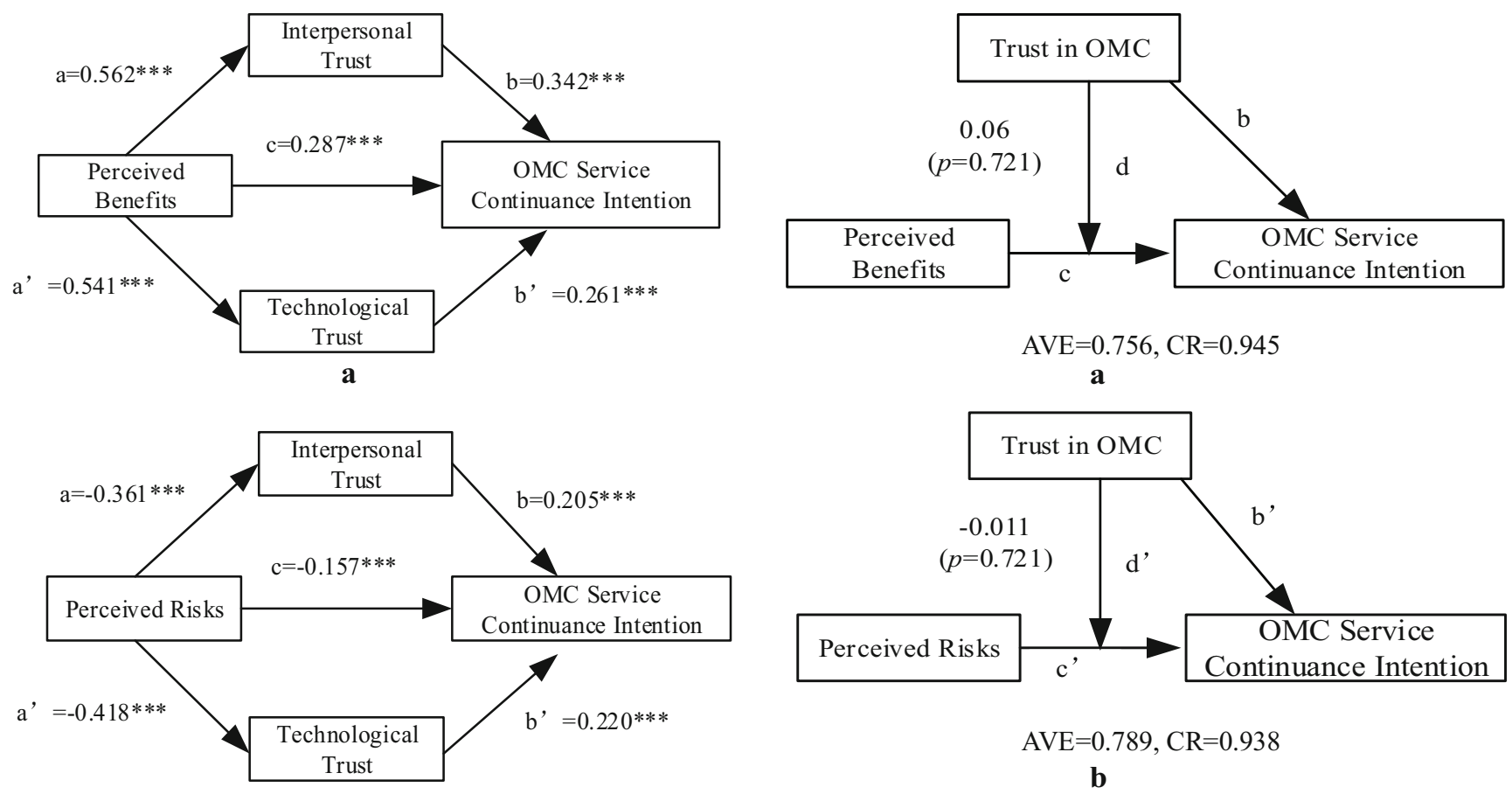

Fig. 3 a. b Moderating Effect of Trust in OMC

the formation of such a trusting attitude depends on patients' risk-benefit evaluation of the OMC.

\subsection{Practical Implications}

increasing the OMC service continuance intention. In particular, our findings of the partial mediation effect suggest that the interpersonal and technological aspects of online trust may complement each other in studying emerging eservices such as OMC.

Third, our work offers insights into patients' adoption and use of technology-mediated service. The technology adoption perspective suggests that consumers' intentions to use a technology-mediated service are driven primarily by their expectations about service-technology fit (Heinze and Matt 2018). Consumers' formation of these expectations further affects their trusting beliefs through different mechanisms. Complementing this line of research, we compare the direct-cause model, mediation model, and moderation model of trust. The non-significant buffering effect (i.e., the moderation model) implies that patients' service continuance intentions are more likely influenced by a trusting attitude than trusting beliefs that work synergistically with other OMC-related perceptions (Bhattacherjee 2001). The partial mediation indicates that

Our findings also provide several practical implications for online healthcare service delivery. First, interpersonal and technological trust are two effective means to realize the effects of patients' beliefs regarding OMC benefits and risks. Practitioners trying to persuade patients to use the OMC platform or purchase OMC services may first need to convince patients that $\mathrm{OMC}$ is trustworthy, which entails the trustworthiness of both OMC service providers and the technological infrastructure. For example, many OMC platforms have implemented service rating functions to help patients select appropriate doctors. However, the star-based review only provides a generic overview of service satisfaction without differentiating the interpersonal and technological procedures. OMC managers and service providers may need to design a more targeted review and reporting system to allow patients to reveal their OMC experience from different perspectives, so that prospective patients can develop and maintain multidimensional trust.

Second, in terms of the OMC platform design, our findings suggest that perceived validity, patient- 
centeredness, privacy risk, and performance risk are not only important in their own right but can also affect interpersonal trust and technological trust. OMC platforms should design their informational and transactional services with these attributes in mind. For example, privacy risk may be improved via better information disclosure related to data policies. OMC platforms may actively inform patients about how the data will be collected and managed when the patients enter the platform. Similarly, performance risk may be mitigated by providing better customer support from the platform. Even the doctors' performance may not be satisfactory - thus reducing interpersonal trust - the service failure recovery effort made by the platform may still maintain technological trust, thus maintaining the intention to continue using the platform.

Third, the unsupported moderating role of trust suggests that the OMC service providers should not expect to mitigate privacy and performance risk perceptions by enhancing trusting beliefs toward the OMC. Thus, even if the patients earn trust via other OMC benefits, it cannot alleviate the negative impacts of privacy risk and performance risk. A better approach is to improve actual privacy protection and service performance, which enhances patients' perceived benefits. Overall, this research helps to understand the role trust plays to all OMC stakeholders, including healthcare professionals and digital platform owners, regarding managing patients' risk-benefit evaluation and promoting patient participation in the paid OMC services via enhanced interpersonal and technological trust.

\subsection{Limitations and Future Research}

We have identified several limitations of our research. First, although the extended valence framework that incorporates both risk-benefit evaluation and trust mechanism provides a good explanation of patients' service continuance decisions, various alternative mechanisms may influence the formation of a trusting attitude apart from the current benefit and risk factors. For example, patients may evaluate channel characteristics (e.g., convenience and personalization), customer support, and institutional safeguards. Our literature review in Appendix A gives many examples that fall within the risk-benefit evaluation but are not incorporated into our model. In addition, future research may also investigate cognitive mechanisms other than the risk-benefit appraisal. For example, media naturalness theory (Zahedi et al. 2016) and affect transfer theory (Hernandez et al. 2019) have been used in previous research to understand the formation of trust in the digital context.

Second, since we focus on individual psychological mechanisms, no structural factors are included in our model. Although we carefully included individual-level control variables that help alleviate the confounding effect due to individual differences, we cannot entirely rule out the potential confounding effect from the platform level. For example, the service design (e.g., the freemium business model implemented by many OMCs) may simultaneously influence patients' trust and service continuance intention. Future research may further investigate how platform-level factors differentiate individual appraisals and behaviors on OMC.

Third, our work is conducted in China; thus, the applicability of the outcomes may be constrained by the particular cultural and socio-political context. Moreover, we collect data from a unique user group (i.e., patients from one particular OMC platform), which may subject to sampling bias - for example, our sample includes more younger users who are familiar with smartphone-based healthcare services. Given the global popularity of online healthcare services, future research can examine the model in countries with different social-cultural and political settings, inviting subjects from a more diverse population to validate the generalizability of the research findings.

\section{Conclusion}

In conclusion, this study proposes a multidimensional approach to conceptualize the influences of trust, which includes both interpersonal and technological aspects in the OMC service continuance decision-making. We go beyond the unitary view of trust and draw on the valence framework to examine the underlying psychological mechanisms and the potential synergistic effects of trust with other OMC service-related factors. The different roles of trust (i.e., as a direct cause, a mediator, or a moderator) help clarify the different ways trust may account for patients' service continuance intentions. Considering the vast network of patients and the central role of technology in mediating and supporting the service delivery, OMC managers and service providers should consider both interpersonal and technological aspects of trust through their service to achieve OMC success. 


\section{Appendix A}

Table 9 Selected Literatures on Online Trust

\begin{tabular}{|c|c|c|c|c|c|}
\hline \multirow[t]{2}{*}{ Study } & \multicolumn{2}{|l|}{ Variables related to } & \multirow[t]{2}{*}{ Other variables } & \multirow[t]{2}{*}{ Theory } & \multirow[t]{2}{*}{ Key findings } \\
\hline & Interpersonal trust & $\begin{array}{l}\text { Technological } \\
\text { trust }\end{array}$ & & & \\
\hline $\begin{array}{l}\text { Sollner et al. } \\
\text { (2016) }\end{array}$ & $\begin{array}{l}\text { Trust in the Internet } \\
\text { (IV), Trust in the } \\
\text { community of } \\
\text { Internet users (IV), } \\
\text { Trust in the provider } \\
\text { (Mev) }\end{array}$ & $\begin{array}{l}\text { Trust in the } \\
\text { information } \\
\text { system (DV) }\end{array}$ & $\begin{array}{l}\text { Perceived usefulness (Mev), perceived } \\
\text { ease of use (DV), intention to use } \\
\text { (DV) }\end{array}$ & Trust-TAM & $\begin{array}{l}\text { TRUST_INET } \rightarrow \text { TRUST } \\
\text { COMM }(+) \\
\text { TRUST_INET } \rightarrow \text { TRUST } \\
\text { PROV } \rightarrow \text { TRUST_IS }(+) \\
\text { TRUST_IS } \rightarrow \text { PU } \rightarrow \text { INT }_{-} \\
\text {USE }(+) \\
\text { TRUST_PROV } \rightarrow \\
\text { PU } \rightarrow \text { INT_USE }(+) \\
\text { TRUST_PROV } \rightarrow \text { PEOU }(+) \\
\text { PEOU } \rightarrow \text { PU } \rightarrow \text { INT_USE }(+) \\
\text { PEOU } \rightarrow \text { TRUST_IS } \rightarrow \text { PU } \\
(+)\end{array}$ \\
\hline $\begin{array}{l}\text { Ou et al. } \\
\quad(2014)\end{array}$ & Trust in seller (IV) & - & $\begin{array}{l}\text { Effective Use of Instant Messenger } \\
\text { (IV), effective use of message box } \\
\text { (IV), effective use of feedback } \\
\text { system (IV), interactivity (IV), swift } \\
\text { guanxi (IV), presence (IV), } \\
\text { repurchase intentions (DV), actual } \\
\text { repurchases (DV) }\end{array}$ & $\begin{array}{l}\text { The media synchronicity } \\
\text { theory }\end{array}$ & $\begin{array}{l}\text { Effective use of instant } \\
\text { messenger, effective use of } \\
\text { message box, effective use } \\
\text { of feedback system } \rightarrow \\
\text { Interactivity, presence (+) } \\
\text { Interactivity, presence } \rightarrow \text { Swift } \\
\text { Guanxi, trust (+) } \\
\text { Swift Guanxi, trust } \rightarrow \\
\text { Repurchase intentions } \\
\text { (DV), actual repurchases } \\
\text { (DV) (+) }\end{array}$ \\
\hline $\begin{array}{l}\text { Fang et al. } \\
\text { (2014) }\end{array}$ & Trust in vendor (Mev) & - & $\begin{array}{l}\text { Satisfaction with vendor (IV), } \\
\text { perceived effectiveness of } \\
\text { institutional mechanisms (PEEIM) } \\
\text { (Mov), repurchase intention (DV) }\end{array}$ & $\begin{array}{l}\text { The theory of } \\
\text { organizational trust }\end{array}$ & $\begin{array}{l}\text { Satisfaction } \rightarrow \text { Trust } \rightarrow \\
\text { Repurchase intention }(+) \\
\text { PEEIM negatively moderates } \\
\text { the relationship between } \\
\text { trust in an online vendor and } \\
\text { customer repurchase. }(-) \\
\text { PEEIM positively moderates } \\
\text { the relationship between } \\
\text { customer satisfaction and } \\
\text { trust. }(+)\end{array}$ \\
\hline Kim (2014) & $\begin{array}{l}\text { Pre e-vendor trust (IV), } \\
\text { Post e-vendor trust } \\
\text { (IV) }\end{array}$ & $\begin{array}{l}\text { Pre e-channel trust } \\
\text { (IV), Post } \\
\text { e-channel trust } \\
\text { (IV) }\end{array}$ & $\begin{array}{l}\text { Trust propensity (IV), e-vendor } \\
\text { satisfaction (IV), e-vendor delivery } \\
\text { fulfilment (IV), e-channel } \\
\text { satisfaction (IV), e-channel } \\
\text { expectation (IV), e-channel } \\
\text { performance (IV), e-vendor } \\
\text { performance (IV), e-channel reuse } \\
\text { intention (DV), repurchase } \\
\text { intention (DV) }\end{array}$ & $\begin{array}{l}\text { Expectation-confirmation } \\
\text { theory, social exchange } \\
\text { theory }\end{array}$ & $\begin{array}{l}\text { Trust propensity } \rightarrow \text { pre } \\
\text { e-channel trust, pre } \\
\text { e-vendor trust, post } \\
\text { e-channel trust } \\
\text { Post e-channel trust } \rightarrow \text { post } \\
\text { e-vendor trust, e-channel } \\
\text { reuse intention } \\
\text { Pre e-vendor trust } \rightarrow \text { post } \\
\text { e-vendor trust, e-vendor } \\
\text { satisfaction, e-vendor } \\
\text { delivery fulfillment } \\
\text { Pre e-channel trust } \rightarrow \text { pre } \\
\text { e-vendor trust, post } \\
\text { e-channel trust, e-channel } \\
\text { satisfaction, e-channel } \\
\text { expectation }\end{array}$ \\
\hline
\end{tabular}


Table 9 (continued)

\begin{tabular}{lllll}
\hline Study & Variables related to & Other variables & Theory & Key findings \\
\cline { 2 - 3 } Interpersonal trust & $\begin{array}{l}\text { Technological } \\
\text { trust }\end{array}$ & & \\
\end{tabular}

E-channel satisfaction $\rightarrow$ post e-channel trust, e-channel reuse intention

E-vendor satisfaction $\rightarrow$ post e-vendor trust, repurchase intention

E-channel expectation $\rightarrow$ e-channel confirmation

E-vendor delivery fulfillment $\rightarrow$ e-vendor confirmation

E-channel performance $\rightarrow$ e-channel confirmation

E-vendor performance $\rightarrow$ e-vendor confirmation

E-channel confirmation $\rightarrow$ e-channel satisfaction

E-vendor confirmation $\rightarrow$ e-vendor satisfaction

Post e-vendor trust $\rightarrow$ repurchase intention

Lankton et Human-like trusting al. (2015) beliefs (IV)

Venkatesh

et al.

(2016)
System-like trusting beliefs (IV)
Technology humanness (Mov, IV), perceived usefulness (DV), enjoyment (DV), trusting intention (DV), continuance intention (DV), social presence (DV), animation (DV), interpersonal communication (DV), dynamism (DV)
Trust, social presence, and affordance theories Perceived usefulness, trusting intention (+)

System-like trusting beliefs $\rightarrow$ Perceived usefulness, enjoyment, trusting intention, continuance intention $(+)$

The more human-like the technology, the stronger the influence of human-like trusting beliefs. $(+)$

The more system-like the technology, the stronger the influence of system-like trusting beliefs. (+)

Technology humanness $\rightarrow$ Social presence, animation, interpersonal

communication, dynamism Information quality characteristics, channel characteristics $\rightarrow$ Trust, transparency $\rightarrow$ Intention to use E-government (+)

Intention to use E-government $\rightarrow$ Use of E-government $(+)$

Use of E-government $\rightarrow$ Satisfaction with E-government (+)

Transparency and trust mediate moderate the effects of information quality and channel characteristics on intentions. (+) 
Table 9 (continued)

\begin{tabular}{|c|c|c|c|c|c|}
\hline \multirow[t]{2}{*}{ Study } & \multicolumn{2}{|l|}{ Variables related to } & \multirow[t]{2}{*}{ Other variables } & \multirow[t]{2}{*}{ Theory } & \multirow[t]{2}{*}{ Key findings } \\
\hline & Interpersonal trust & $\begin{array}{l}\text { Technological } \\
\text { trust }\end{array}$ & & & \\
\hline $\begin{array}{l}\text { Xu et al. } \\
\text { (2016) }\end{array}$ & $\begin{array}{l}\text { Trust Benevolence (IV), } \\
\text { Trust Integrity (IV), } \\
\text { Trust Competence } \\
\text { (IV) }\end{array}$ & - & $\begin{array}{l}\text { Satisfaction (DV), Purchase behavior } \\
\text { (DV) }\end{array}$ & trust theory & $\begin{array}{l}\text { A buyer's belief about a } \\
\text { seller's benevolence } \rightarrow \\
\text { Satisfaction }(+) \\
\text { A buyer's belief about a } \\
\text { seller's competence } \rightarrow \\
\text { Purchase behavior }(+)\end{array}$ \\
\hline $\begin{array}{l}\text { Wang and } \\
\text { Benbasat } \\
\text { (2016) }\end{array}$ & $\begin{array}{l}\text { Trust in } \\
\text { RA-benevolence } \\
\text { (DV), Trust in } \\
\text { RA-integrity (DV), } \\
\text { Trust in } \\
\text { RA-competence } \\
\text { (DV) }\end{array}$ & - & $\begin{array}{l}\text { Advice quality (IV), perceived } \\
\text { cognitive effort (IV), perceived } \\
\text { strategy restrictiveness (IV), } \\
\text { perceived RA transparency (IV) }\end{array}$ & attribution theory & $\begin{array}{l}\text { Advice Quality } \rightarrow \text { Trust in } \\
\text { RA-competence }(+) \\
\text { Perceived Cognitive Effort } \rightarrow \\
\text { Trust in RA-competence }(+) \\
\text { Perceived Strategy } \\
\text { Restrictiveness } \rightarrow \text { Trust in } \\
\text { RA-competence }(+) \\
\text { Perceived RA transparency } \rightarrow \\
\text { Trust in RA-competence, } \\
\text { integrity, competence }(+) \\
\text { Perceived RA Transparency } \\
\rightarrow \text { Perceived cognitive } \\
\text { effort }(-) \\
\text { Perceived RA transparency } \rightarrow \\
\text { Advice quality }(+)\end{array}$ \\
\hline $\begin{array}{l}\text { Hoque et al. } \\
\text { (2017) }\end{array}$ & - & Trust (IV) & $\begin{array}{l}\text { Perceived ease of use (IV), perceived } \\
\text { usefulness (IV), privacy (IV), } \\
\text { gender (Mev), intention to use (DV) }\end{array}$ & Extended TAM & $\begin{array}{l}\text { Perceived ease of use } \rightarrow \\
\text { Intention to use }(+) \\
\text { Perceived usefulness } \rightarrow \\
\quad \text { Intention to use }(+) \\
\text { Privacy } \rightarrow \text { Intention to use (ns) } \\
\text { Trust } \rightarrow \text { Intention to use }(+) \\
\text { Gender } \rightarrow \text { Intention to use }(+)\end{array}$ \\
\hline $\begin{array}{l}\text { Fan and } \\
\text { Lederma- } \\
\text { n (2018) }\end{array}$ & - & $\begin{array}{l}\text { Affective trust } \\
\text { (IV), Cognitive } \\
\text { trust (IV) }\end{array}$ & $\begin{array}{l}\text { Information adoption (DV), formation } \\
\text { of relational closeness (DV) }\end{array}$ & Social capital theory & $\begin{array}{l}\text { Affective trust } \rightarrow \text { Information } \\
\text { adoption }(+) \\
\text { Affective trust } \rightarrow \text { Formation of } \\
\text { relational closeness }(+) \\
\text { Cognitive trust } \rightarrow \text { Information } \\
\text { adoption }(+)\end{array}$ \\
\hline $\begin{array}{l}\text { Park and } \\
\text { Lee } \\
(2018)\end{array}$ & $\begin{array}{l}\text { Trust in government } \\
\text { information (IV) }\end{array}$ & - & $\begin{array}{l}\text { Application acceptance (DV), } \\
\text { performance expectancy (IV), effort } \\
\text { expectancy (IV) }\end{array}$ & $\begin{array}{l}\text { The unified theory of } \\
\text { acceptance and use of } \\
\text { technology }\end{array}$ & $\begin{array}{l}\text { Trust in government } \\
\text { information } \rightarrow \text { Performance } \\
\text { expectancy }(+) \\
\text { Trust in government } \\
\text { information } \rightarrow \text { Effort } \\
\text { expectancy }(+) \\
\text { Performance expectancy } \rightarrow \\
\text { Application acceptance }(+) \\
\text { Effort expectancy } \rightarrow \\
\text { Application acceptance }(+)\end{array}$ \\
\hline $\begin{array}{l}\text { Lu et al. } \\
\quad(2018)\end{array}$ & - & $\begin{array}{l}\text { Cognition-based } \\
\text { trust (IV), } \\
\text { affect-based } \\
\text { trust (IV) }\end{array}$ & $\begin{array}{l}\text { Internet health information quality } \\
\text { (IV), source of information (IV), } \\
\text { patient compliance (DV) }\end{array}$ & $\begin{array}{l}\text { The social information } \\
\text { processing theory and } \\
\text { social exchange theory }\end{array}$ & $\begin{array}{l}\text { Internet health information } \\
\text { quality } \rightarrow \text { Cognition-based } \\
\text { trust }(+) \\
\text { Internet health information } \\
\text { quality } \rightarrow \text { Affect-based } \\
\text { trust }(+) \\
\text { Source of information } \rightarrow \\
\text { Cognition-based trust }(+) \\
\text { Source of information } \rightarrow \\
\text { Affect-based trust }(\mathrm{ns})\end{array}$ \\
\hline
\end{tabular}


Table 9 (continued)

\begin{tabular}{lllll}
\hline Study & Variables related to & Other variables & Theory & Key findings \\
\cline { 2 - 3 } Interpersonal trust & $\begin{array}{l}\text { Technological } \\
\text { trust }\end{array}$ & &
\end{tabular}

\begin{tabular}{|c|c|c|}
\hline $\begin{array}{r}\text { Lee et al. } \\
(2018)\end{array}$ & $\begin{array}{l}\text { Trust in } \\
\text { newspapers/- } \\
\text { magazines, radio, }\end{array}$ & $\begin{array}{l}\text { Trust in doctors, } \\
\text { Trust in } \\
\text { family/friends }\end{array}$ \\
\hline
\end{tabular}

Deng et al. (2018)

Tams et al. (2018)

Meng et al.
(2019a, 2019b)

Trust (IV)
Trust in functionality (IV), Trust in helpfulness (IV), Trust in reliability (IV)

Trust in mobile health services (IV)
Perceived ease of use (IV), perceived usefulness (IV), perceived Risk

(IV), adoption intention (DV)

Internal CSE (Computer Self-efficacy) (Mev), External CSE (Mev), Trying to Innovate (DV), Deep Use (DV)

The Model of Proactive Work Behavior (MPWB)

Channel

Complementarity

Theory

Extended TAM hospital support (Mev), intention to use mHealth services (DV)
Cognition-based trust $\rightarrow$ Affect-based trust $(+)$

Cognition-based trust $\rightarrow$ Patient compliance (ns)

Affect-based trust $\rightarrow$ Patient compliance $(+)$

Trust in doctors $\rightarrow$ trust in all channels, except the Internet (+)

Trust in family/friends $\rightarrow$ trust in all channels, except the Internet (+)

Trust in newspapers $\rightarrow$ trust in all channels $(+)$

Trust in radio $\rightarrow$ trust in all channels (+)

Trust in $\mathrm{TV} \rightarrow$ trust in all channels (+)

Trust in the Internet. $\rightarrow$ trust in all channels, except the doctors and family/friends $(+)$

Trust $\rightarrow$ Adoption intention $(+)$

Perceived usefulness $\rightarrow$ Trust (ns)

Perceived usefulness $\rightarrow$ Adoption intention (+)

Perceived ease of use $\rightarrow$ Trust (ns)

Perceived ease of use $\rightarrow$ Adoption intention (+)

Perceived Risk $\rightarrow$ Trust $(-)$

Perceived Risk $\rightarrow$ Adoption intention (-)

Trust in helpfulness $\rightarrow$ External CSE $\rightarrow$ Deep structure $(+)$

Trust in reliability $\rightarrow$ External $\mathrm{CSE} \rightarrow$ Deep structure (+)

Trust in functionality $\rightarrow$ Internal CSE $\rightarrow$ Deep structure $(+)$

Trust in functionality $\rightarrow$ Internal CSE $\rightarrow$ Trying to innovate $(+)$

Trust in offline health services $\rightarrow$ Trust in mHealth services (+)

Trust in mHealth services $\rightarrow$ Intention to use mHealth services (+)

Physiological conditions $\rightarrow$ Trust in mHealth services (+) 
Table 9 (continued)

\begin{tabular}{|c|c|c|c|c|c|}
\hline \multirow[t]{2}{*}{ Study } & \multicolumn{2}{|l|}{ Variables related to } & \multirow[t]{2}{*}{ Other variables } & \multirow[t]{2}{*}{ Theory } & \multirow[t]{2}{*}{ Key findings } \\
\hline & Interpersonal trust & $\begin{array}{l}\text { Technological } \\
\text { trust }\end{array}$ & & & \\
\hline $\begin{array}{r}\text { Odusanya et } \\
\text { al. (2020) }\end{array}$ & - & $\begin{array}{l}\text { Trust in e-retail } \\
\text { platforms (IV) }\end{array}$ & $\begin{array}{l}\text { PU, PEU, Information quality (IQ), } \\
\text { Perceived risk (PR), Social } \\
\text { influence (SI), Hedonic motivation } \\
\text { (HM), Continuance Intention to use } \\
\text { (DV) }\end{array}$ & Trust building theory & $\begin{array}{l}\text { PU, PEU, IQ } \rightarrow \text { Trust } \\
\quad(+) \rightarrow \text { Continuance } \\
\text { Intention } \\
\text { PR }(-) \rightarrow \text { Trust } \\
\quad(+) \rightarrow \text { Continuance } \\
\text { Intention } \\
\text { SI, HM }(+) \rightarrow \text { Trust }\end{array}$ \\
\hline $\begin{array}{l}\text { Gong et al. } \\
\text { (2020) }\end{array}$ & Emotional trust (IV) & $\begin{array}{l}\text { Cognitive trust } \\
\text { (IV) }\end{array}$ & $\begin{array}{l}\text { Perceived entitativity (PE), Intention to } \\
\text { use mobile payment (DV) }\end{array}$ & The trust transfer theory & $\begin{array}{l}\text { PE }(+) \rightarrow \text { Cognitive trust \& } \\
\text { Emotional trust } \rightarrow \text { Intention } \\
\text { to use }\end{array}$ \\
\hline $\begin{array}{l}\text { Yang et al. } \\
\text { (2020) }\end{array}$ & - & $\begin{array}{l}\text { Trust in platform } \\
\text { (IV) }\end{array}$ & $\begin{array}{l}\text { Service quality (SQ), Perceived risk } \\
\text { (PR), Intention to upgrade to paid } \\
\text { OMC (DV) }\end{array}$ & $\begin{array}{l}\text { Extended valence } \\
\text { framework }\end{array}$ & $\begin{array}{l}\text { SQ } \rightarrow \text { trust } \rightarrow \text { Intention to } \\
\text { upgrade }(+) \\
\text { PR }(-) \rightarrow \text { Trust } \rightarrow \text { Intention to } \\
\text { upgrade }(+)\end{array}$ \\
\hline
\end{tabular}

Note: The selected studies are collected from the year of 2014, since Kim (2014) had listed most of the studies of online trust that published before the year of 2014

\section{Appendix B. Measurement Items for the Constructs}

Note: we use $\mathrm{ABC}$ as a pseudo name for the OMC platform we studied. 7-point Likert scales with 1 as strongly disagree, and 7 as strongly agree are used.

Perceived Benefits [PB].

1. $[\mathrm{ABC}]$ can improve the overall quality of my healthcare experience.

2. Using $[A B C]$ is beneficial.

3. Using $[\mathrm{ABC}]$ can save me time and costs.

Perceived Validity [PV].

1. Physicians at $[\mathrm{ABC}]$ deliver the consultation service in a timely fashion as promised.

2. Physicians at $[A B C]$ can fulfill my consultation orders.

3 . The service by $[\mathrm{ABC}]$ is excellent.

Perceived Centeredness [PC].

1. The service provides me a personalized experience.

2. $[\mathrm{ABC}]$ can address the special needs of each customer.

3. I was satisfied with the customization options in the service.

Perceived Risks [PR].

1. Using $[A B C]$ is risky.

2. Overall, how risky would it be to use $[\mathrm{ABC}]$ ? (not risky at all - very risky).

3 . Use $[A B C]$ exposes me to risk (improbable - very probable).

4. Use $[A B C]$ would add considerable uncertainty to my healthcare experience.
Privacy Risk [Prr].

1. The chances of losing privacy control are high when I use $[\mathrm{ABC}]$.

2. My personal information may be used without my knowledge when use $[\mathrm{ABC}]$.

3. The risk of unauthorized access to my health records is high if I use [ABC].

Performance Risk [Per].

1. The physicians at $[\mathrm{ABC}]$ might not perform well.

2. The probability of receiving poor services from physicians at $[\mathrm{ABC}]$ is high.

3. It is risky to use $[A B C]$ as the expected level of service performance is low.

Competence [C].

1. Physicians at $[\mathrm{ABC}]$ is competent in providing healthcare consulting services.

2. Physicians at $[\mathrm{ABC}]$ understand the needs of patients it serves.

3. Physicians at $[\mathrm{ABC}]$ are knowledgeable in providing health consultation services.

Benevolence [B].

1. Physicians at $[\mathrm{ABC}]$ would act in my best interest.

2. Physicians at $[A B C]$ would do their best to help me.

3. Physicians at $[\mathrm{ABC}]$ are respectful of my well-being.

Integrity [In].

1. Promises made by physicians at $[\mathrm{ABC}]$ are reliable.

2. Physicians at $[\mathrm{ABC}]$ as honest.

3. Physicians at $[\mathrm{ABC}]$ keeps their commitment. 
Functionality [Fun].

1. $[\mathrm{ABC}]$ has the functionalities I need.

2. $[A B C]$ has features required for my tasks.

3. $[\mathrm{ABC}]$ has the overall capabilities I need.

Reliability [Re].

1. $[\mathrm{ABC}]$ has not failed me.

2. $[\mathrm{ABC}]$ has not malfunctioned for me.

3. $[\mathrm{ABC}]$ provides error-free results.

Helpfulness [He].

1. $[\mathrm{ABC}]$ provides the help I need to complete online healthcare consultation tasks successfully.
2. $[\mathrm{ABC}]$ provides competent guidance through the help function.

3. [ABC] supplies my need for help through the help function.

Trust in $O M C$ (mimic items).

1. $[\mathrm{ABC}]$ is trustworthy.

2. I trust $[\mathrm{ABC}]$.

OMC Service Continuance Intention [CI].

1. If I were to buy the OMC again, I would likely buy it from $[\mathrm{ABC}]$.

2. How likely is it that you would subscribe to $[A B C]$ for its paid services in the future? (Not at all - very likely)

\section{Appendix C}

Table 10 Confirmatory Factor Analysis

\begin{tabular}{|c|c|c|c|c|c|c|c|c|c|c|c|c|c|c|c|}
\hline Construct & Item & 1 & 2 & 3 & 4 & 5 & 6 & 7 & 8 & 9 & 10 & 11 & 12 & 13 & 14 \\
\hline \multirow[t]{3}{*}{ 1. $\mathrm{PB}$} & PB1 & 0.865 & 0.395 & 0.417 & -0.331 & -0.285 & -0.316 & 0.388 & 0.391 & 0.397 & 0.421 & 0.386 & 0.414 & 0.559 & 0.548 \\
\hline & PB2 & 0.846 & 0.415 & 0.356 & -0.292 & -0.286 & -0.32 & 0.423 & 0.38 & 0.366 & 0.45 & 0.298 & 0.416 & 0.508 & 0.502 \\
\hline & PB3 & 0.765 & 0.373 & 0.286 & -0.164 & -0.158 & -0.233 & 0.352 & 0.28 & 0.308 & 0.393 & 0.298 & 0.42 & 0.416 & 0.398 \\
\hline \multirow[t]{3}{*}{ 2. PV } & PV1 & 0.455 & 0.876 & 0.466 & -0.212 & -0.177 & -0.331 & 0.396 & 0.39 & 0.397 & 0.513 & 0.378 & 0.535 & 0.439 & 0.371 \\
\hline & PV2 & 0.331 & 0.780 & 0.47 & -0.243 & -0.178 & -0.311 & 0.407 & 0.308 & 0.318 & 0.415 & 0.344 & 0.475 & 0.400 & 0.392 \\
\hline & PV3 & 0.37 & 0.797 & 0.512 & -0.292 & -0.26 & -0.335 & 0.345 & 0.382 & 0.384 & 0.390 & 0.399 & 0.421 & 0.442 & 0.385 \\
\hline \multirow[t]{3}{*}{ 3. $\mathrm{PC}$} & $\mathrm{PC} 1$ & 0.324 & 0.486 & 0.802 & -0.261 & -0.205 & -0.27 & 0.419 & 0.419 & 0.444 & 0.332 & 0.381 & 0.472 & 0.426 & 0.393 \\
\hline & PC2 & 0.352 & 0.397 & 0.792 & -0.273 & -0.269 & -0.243 & 0.383 & 0.467 & 0.483 & 0.28 & 0.358 & 0.39 & 0.363 & 0.333 \\
\hline & PC3 & 0.383 & 0.555 & 0.865 & -0.258 & -0.234 & -0.302 & 0.409 & 0.436 & 0.424 & 0.408 & 0.397 & 0.495 & 0.488 & 0.362 \\
\hline \multirow[t]{4}{*}{ 4. $\mathrm{PR}$} & PR1 & -0.241 & -0.217 & -0.254 & 0.852 & 0.452 & 0.533 & -0.306 & -0.271 & -0.339 & -0.200 & -0.313 & -0.217 & -0.414 & -0.386 \\
\hline & PR2 & -0.378 & -0.311 & -0.296 & 0.812 & 0.506 & 0.598 & -0.370 & -0.376 & -0.381 & -0.314 & -0.401 & -0.312 & -0.463 & -0.402 \\
\hline & PR3 & -0.202 & -0.251 & -0.236 & 0.771 & 0.386 & 0.538 & -0.233 & -0.221 & -0.25 & -0.215 & -0.218 & -0.248 & -0.33 & -0.286 \\
\hline & PR4 & -0.216 & -0.187 & -0.25 & 0.806 & 0.531 & 0.523 & -0.224 & -0.323 & -0.318 & -0.168 & -0.271 & -0.206 & -0.348 & -0.330 \\
\hline \multirow[t]{3}{*}{ 5. Prr } & Prr1 & -0.283 & -0.25 & -0.271 & 0.534 & 0.857 & 0.575 & -0.33 & -0.328 & -0.384 & -0.217 & -0.231 & -0.238 & -0.358 & -0.263 \\
\hline & Prr2 & -0.271 & -0.191 & -0.246 & 0.518 & 0.908 & 0.564 & -0.302 & -0.376 & -0.388 & -0.185 & -0.303 & -0.237 & -0.343 & -0.311 \\
\hline & Prr3 & -0.246 & -0.218 & -0.251 & 0.497 & 0.905 & 0.577 & -0.321 & -0.407 & -0.395 & -0.236 & -0.307 & -0.263 & -0.299 & -0.268 \\
\hline \multirow[t]{3}{*}{ 6. Per } & Per1 & -0.21 & -0.277 & -0.228 & 0.585 & 0.543 & 0.843 & -0.238 & -0.250 & -0.282 & -0.234 & -0.327 & -0.218 & -0.37 & -0.347 \\
\hline & Per2 & -0.355 & -0.382 & -0.337 & 0.58 & 0.576 & 0.870 & -0.421 & -0.400 & -0.421 & -0.373 & -0.316 & -0.416 & -0.486 & -0.364 \\
\hline & Per3 & -0.337 & -0.351 & -0.279 & 0.558 & 0.517 & 0.831 & -0.389 & -0.371 & -0.439 & -0.373 & -0.387 & -0.39 & -0.456 & -0.399 \\
\hline \multirow[t]{3}{*}{ 7. $\mathrm{C}$} & $\mathrm{C} 1$ & 0.378 & 0.361 & 0.353 & -0.262 & -0.239 & -0.299 & 0.818 & 0.420 & 0.480 & 0.453 & 0.367 & 0.497 & 0.472 & 0.314 \\
\hline & $\mathrm{C} 2$ & 0.39 & 0.400 & 0.372 & -0.279 & -0.297 & -0.297 & 0.683 & 0.504 & 0.435 & 0.378 & 0.452 & 0.433 & 0.339 & 0.386 \\
\hline & C3 & 0.292 & 0.293 & 0.391 & -0.263 & -0.285 & -0.337 & 0.743 & 0.412 & 0.447 & 0.338 & 0.299 & 0.395 & 0.37 & 0.31 \\
\hline \multirow[t]{3}{*}{ 8. B } & B1 & 0.306 & 0.326 & 0.394 & -0.308 & -0.373 & -0.35 & 0.437 & 0.789 & 0.485 & 0.319 & 0.381 & 0.39 & 0.393 & 0.252 \\
\hline & B2 & 0.394 & 0.356 & 0.416 & -0.316 & -0.338 & -0.341 & 0.484 & 0.811 & 0.476 & 0.317 & 0.375 & 0.41 & 0.415 & 0.314 \\
\hline & B3 & 0.316 & 0.369 & 0.467 & -0.261 & -0.278 & -0.263 & 0.469 & 0.779 & 0.49 & 0.316 & 0.405 & 0.372 & 0.408 & 0.277 \\
\hline \multirow[t]{3}{*}{ 9. In } & In1 & 0.412 & 0.38 & 0.489 & -0.365 & -0.385 & -0.392 & 0.483 & 0.54 & 0.845 & 0.348 & 0.485 & 0.468 & 0.463 & 0.326 \\
\hline & $\operatorname{In} 2$ & 0.347 & 0.353 & 0.442 & -0.297 & -0.296 & -0.307 & 0.502 & 0.464 & 0.825 & 0.353 & 0.39 & 0.431 & 0.426 & 0.265 \\
\hline & In 3 & 0.332 & 0.396 & 0.445 & -0.345 & -0.416 & -0.424 & 0.537 & 0.526 & 0.845 & 0.363 & 0.421 & 0.5 & 0.438 & 0.299 \\
\hline \multirow[t]{3}{*}{ 10. Fun } & Ful & 0.476 & 0.454 & 0.319 & -0.244 & -0.21 & -0.324 & 0.432 & 0.334 & 0.365 & 0.836 & 0.43 & 0.556 & 0.389 & 0.336 \\
\hline & Fu2 & 0.29 & 0.333 & 0.299 & -0.223 & -0.185 & -0.261 & 0.407 & 0.344 & 0.3 & 0.715 & 0.377 & 0.429 & 0.323 & 0.266 \\
\hline & Fu3 & 0.419 & 0.477 & 0.363 & -0.193 & -0.168 & -0.316 & 0.396 & 0.271 & 0.329 & 0.799 & 0.434 & 0.521 & 0.374 & 0.296 \\
\hline \multirow[t]{3}{*}{ 11. Re } & Re1 & 0.333 & 0.475 & 0.483 & -0.307 & -0.208 & -0.33 & 0.439 & 0.433 & 0.458 & 0.528 & 0.786 & 0.52 & 0.381 & 0.315 \\
\hline & Re2 & 0.289 & 0.263 & 0.285 & -0.24 & -0.257 & -0.261 & 0.335 & 0.349 & 0.39 & 0.334 & 0.771 & 0.432 & 0.253 & 0.247 \\
\hline & Re3 & 0.315 & 0.303 & 0.29 & -0.332 & -0.289 & -0.352 & 0.369 & 0.36 & 0.367 & 0.356 & 0.814 & 0.423 & 0.329 & 0.385 \\
\hline \multirow[t]{3}{*}{ 12. $\mathrm{He}$} & He1 & 0.411 & 0.507 & 0.447 & -0.31 & -0.284 & -0.38 & 0.504 & 0.402 & 0.45 & 0.538 & 0.558 & 0.833 & 0.44 & 0.397 \\
\hline & $\mathrm{He} 2$ & 0.306 & 0.433 & 0.428 & -0.196 & -0.186 & -0.276 & 0.456 & 0.378 & 0.416 & 0.425 & 0.392 & 0.716 & 0.336 & 0.258 \\
\hline & He3 & 0.432 & 0.4 & 0.397 & -0.182 & -0.152 & -0.256 & 0.399 & 0.355 & 0.417 & 0.509 & 0.379 & 0.747 & 0.367 & 0.282 \\
\hline \multirow[t]{2}{*}{ 13. TP } & TP1 & 0.549 & 0.518 & 0.522 & -0.454 & -0.332 & -0.463 & 0.483 & 0.469 & 0.489 & 0.44 & 0.4 & 0.47 & 0.917 & 0.56 \\
\hline & TP2 & 0.554 & 0.433 & 0.428 & -0.43 & -0.356 & -0.479 & 0.49 & 0.466 & 0.478 & 0.406 & 0.362 & 0.446 & 0.912 & 0.542 \\
\hline \multirow[t]{2}{*}{ 14. CI } & CPI1 & 0.537 & 0.401 & 0.427 & -0.402 & -0.312 & -0.381 & 0.383 & 0.328 & 0.329 & 0.309 & 0.361 & 0.352 & 0.562 & 0.918 \\
\hline & CPI2 & 0.544 & 0.448 & 0.38 & -0.398 & -0.266 & -0.418 & 0.427 & 0.323 & 0.322 & 0.394 & 0.383 & 0.407 & 0.544 & 0.916 \\
\hline
\end{tabular}




\section{Appendix D}

Table 11 Summary of Hypotheses and Findings

\begin{tabular}{ll}
\hline Hypothesis & Results \\
\hline H1: Perceived benefits of OMC, comprised of perceived validity and patient-centeredness, & Supported \\
has a positive impact & \\
on patients' OMC service continuance intention. & \\
H2: Perceived risks of OMC, consisting of perceived privacy risk and perceived performance & Supported \\
risk, negatively & \\
impacts patients' OMC service continuance intention. & Supported \\
H3: Interpersonal trust, consisting of competence, benevolence, and integrity, positively & \\
impacts & \\
patients' OMC service continuance intention. & Supported \\
H4: Technological trust, consisting of functionality, reliability, and helpfulness, positively & \\
impacts patients' & \\
OMC service continuance intention. & Supported \\
H5: Trust in OMC, consisting of interpersonal and technological trust, mediates the positive & \\
relationship & \\
between perceived benefits and patients' OMC service continuance intention. & \\
H6: Trust in OMC, consisting of interpersonal and technological trust, mediates the negative & Supported \\
relationship & \\
between perceived risks and patients' OMC service continuance intention. & \\
H7: Trust moderates the positive relationship between perceived benefits and patients' OMC & Not Supported \\
service continuance intention. & \\
H8: Trust moderates the negative relationship between perceived risks and patients' OMC & Not Supported \\
service continuance intention. & \\
\hline
\end{tabular}

\section{Appendix E. Gaussian Copula Analysis}

The goal of our research model is to explain the effects of perceived benefits $(\mathrm{PB})$ and perceived risks $(\mathrm{PR})$ on trust and ultimately on patients' OMC service continuance intention (CI). Accordingly, our research model includes two partial regression models: (1) CI is regressed on PB, PR, and Trust; (2) Trust is regressed on PB and PR. In this post hoc analysis, we focus on the first, more complex model.

We first verify if we meet the assumptions of Gaussian copula analysis (i.e., variables exhibit endogeneity should be non-normally distributed). We use the standardized composite scores (i.e., PB, PR, and Trust) provided by the PLS estimation to test variable nonnormality using the KolmogorovSmirnov test with the Lilliefors correction (Sarstedt and Mooi 2014). The results show that none of the construct scores are normally distributed, thus meeting the assumption of conducting the Gaussian copula analysis.

Next, we build three regression models using PB (model 1), PR (Model 2), and Trust (Model 3) as independent variables that possibly exhibit endogeneity. We also create four regression models that include all possible combinations of these constructs to capture multiple endogenous factors simultaneously: PB and PR (Model 4), PR and Trust (Model 5), PB and Trust (Model 6), and PB, PR, and Trust (Model 7). The constructs' standardized composite scores are then used to compute the Gaussian copula of the partial regressions in the structural model. Following Hult et al.'s (2018) instruction and using the companion $\mathrm{R}$ codes provided in the article, ${ }^{3}$ we implement the models using the REndo package of the $\mathrm{R}$ program. The copula is the inverse of the Gaussian normal cumulative distribution function. In Gaussian copula analysis, the regression models are estimated by incorporating the copula as an additional independent variable that controls the correlation between the error term and the endogenous independent construct in the regression model. The results in Table E1 show that no Gaussian copula is significant, thus, ruling out the potential endogeneity issue caused by omitted variables.

\footnotetext{
${ }^{3}$ The R codes can be found here: https://www.pls-sem.net/pls-sem-academy/ gaussian-copula-files/
} 
Table 12 Results of the Gaussian Copula Analysis

\begin{tabular}{|c|c|c|c|c|c|c|c|c|c|c|c|c|c|c|c|c|}
\hline \multirow[b]{2}{*}{ Variable } & \multicolumn{2}{|c|}{ Original Model } & \multicolumn{2}{|c|}{$\begin{array}{l}\text { Gaussian } \\
\text { Copula Model } \\
1 \text { (Endogenous } \\
\text { Variable: PB) }\end{array}$} & \multicolumn{2}{|c|}{$\begin{array}{l}\text { Gaussian } \\
\text { Copula Model } \\
2 \text { (Endogenous } \\
\text { Variable: PR) }\end{array}$} & \multicolumn{2}{|c|}{$\begin{array}{l}\text { Gaussian } \\
\text { Copula Model } \\
3 \text { (Endogenous } \\
\text { Variable: Trust) }\end{array}$} & \multicolumn{2}{|c|}{$\begin{array}{l}\text { Gaussian } \\
\text { Copula Model } \\
4 \text { (Endogenous } \\
\text { Variable: PR } \\
\text { and PB) }\end{array}$} & \multicolumn{2}{|c|}{$\begin{array}{l}\text { Gaussian } \\
\text { Copula Model } \\
5 \text { (Endogenous } \\
\text { Variable: PR } \\
\text { and Trust) }\end{array}$} & \multicolumn{2}{|c|}{$\begin{array}{l}\text { Gaussian } \\
\text { Copula Model } \\
6 \text { (Endogenous } \\
\text { Variable: PB } \\
\text { and Trust) }\end{array}$} & \multicolumn{2}{|c|}{$\begin{array}{l}\text { Gaussian } \\
\text { Copula Model } \\
7 \text { (Endogenous } \\
\text { Variable: PB, } \\
\text { PR and Trust) }\end{array}$} \\
\hline & alue & $\begin{array}{l}p \\
\text { value }\end{array}$ & Value & $\begin{array}{l}\mathrm{P} \\
\text { value }\end{array}$ & Value & $\begin{array}{l}p \\
\text { value }\end{array}$ & lue & $\begin{array}{l}p \\
\text { value }\end{array}$ & e & $\begin{array}{l}p \\
\text { value }\end{array}$ & ue & $\begin{array}{l}p \\
\text { value }\end{array}$ & Value & $\begin{array}{l}p \\
\text { value }\end{array}$ & Value & $\begin{array}{l}p \\
\text { value }\end{array}$ \\
\hline B & 0.418 & $<.001$ & 0.710 & $<.001$ & 0.417 & $<.001$ & 0.710 & $<.001$ & $0.41 J$ & $<.001$ & 0.410 & $<.001$ & 0.710 & $<.001$ & & $<.001$ \\
\hline PR & -0.171 & $<.001$ & -0.171 & $<.001$ & -0.181 & $<.001$ & -0.175 & $<.001$ & -0.172 & $<.001$ & -0.173 & $<.001$ & -0.173 & $<.001$ & -0.173 & $<.001$ \\
\hline Trust & 0.318 & $<.001$ & 0.318 & $<.001$ & 0.318 & $<.001$ & 0.311 & $<.001$ & 0.321 & $<.001$ & 0.319 & $<.001$ & 0.319 & $<.001$ & 0.319 & $<.001$ \\
\hline $\mathrm{C}_{\mathrm{PB}}{ }^{a}$ & & & 0.003 & 0.779 & & & & & 0.006 & 0.873 & & & 0.005 & 0.452 & 0.005 & 0.479 \\
\hline $\mathrm{C}_{\mathrm{PR}}$ & & & & & -0.002 & 0.376 & & & -0.007 & 0.659 & -0.007 & 0.713 & & & -0.009 & 0.649 \\
\hline $\mathrm{C}_{\text {Trust }}$ & & & & & & & 0.032 & 0.159 & & & 0.037 & 0.245 & 0.039 & 0.347 & 0.042 & 0.397 \\
\hline
\end{tabular}

Note ${ }^{a} \mathrm{C}$ represents the Gaussian copula (i.e., $\mathrm{C}_{\mathrm{PB}}$ is the Gaussian copula of $\mathrm{PB}$ )

Acknowledgments This work was supported in part by grants from the National Natural Science Foundation of China (Nos. 71571180, $61602536,71874215,72072194)$ offered to the first author.

\section{References}

Agarwal, R., \& Prasad, J. (1998). The antecedents and consequents of user perceptions in information technology adoption. Decision Support Systems, 22(1), 15-29.

Akter, S., D’Ambra, J., \& Ray, P. (2011). Trustworthiness in mhealth information services: An assessment of a hierarchical model with mediating and moderating effects using partial least squares (PLS). Journal of the American Society for Information Science and Technology, 62(1), 100-116.

Anderson, C. L., \& Agarwal, R. (2011). The digitization of healthcare: Boundary risks, emotion, and consumer willingness to disclose personal health information. Information Systems Research, 22(3), 469-490.

Bansal, G., Zahedi, F., \& Gefen, D. (2015). The role of privacy assurance mechanisms in building trust and the moderating role of privacy concern. European Journal of Information Systems, 24(6), 624-644.

Bansal, G., Zahedi, F. M., \& Gefen, D. (2016). Do context and personality matter? Trust and privacy concerns in disclosing private information online. Information \& Management, 53(1), 1-21.

Baron, R. M., \& Kenny, D. A. (1986). The moderator-mediator variable distinction in social psychological research: Conceptual, strategic, and statistical considerations. Journal of Personality and Social Psychology, 51(6), 1173-1182.

Benbasat, I., \& Wang, W. (2005). Trust in and adoption of online recommendation agents. Journal of Association of Information Systems, 6(3), 72-101.

Benítez-Amado, J., Henseler, J., \& Roldán, J. L. (2016). How to address endogeneity in partial least squares path modeling. In 22th Americas conference on information systems. AMCIS, 2016.

Bhattacherjee, A. (2001). Understanding information systems continuance: An expectation-confirmation model. MIS Quarterly, 25(3), 351-370.

Bhattacherjee, A. (2002). Individual trust in online firms: Scale development and initial test. Journal of Management Information Systems, 19(1), 211-241.
Bhattacherjee, A., \& Premkumar, G. (2004). Understanding changes in belief and attitude toward information technology usage: A theoretical model and longitudinal test. MIS Quarterly, 28(2), 229-254.

Bonoma, T. V. (1976). Conflict, cooperation and trust in three power systems. Behavioral Science, 21(6), 499-514.

Cao, X. Y., Liu, Y. M., Zhu, Z. X., Hu, J. H., \& Chen, X. H. (2017). Online selection of a physician by patients: Empirical study from elaboration likelihood perspective. Computers in Human Behavior, 73, 403-412.

Cenfetelli, R. T., \& Bassellier, G. (2009). Interpretation of formative measurement in information systems research. MIS Quarterly, 33(4), 689-707.

Chen, Y., Yang, L. L., Zhang, M., \& Yang, J. (2018). Central or peripheral? Cognition elaboration cues' effect on users' continuance intention of mobile health applications in the developing markets. International Journal of Medical Informatics, 116, 33-45.

Chin, W. W. (1998). Issues and opinion on structural equation modeling. MIS Quarterly, 22(1), 7-16.

Chin, W. W., Marcolin, B. L., \& Newsted, P. R. (2003). A partial least squares latent variable modeling approach for measuring interaction effects: Results from a Monte Carlo simulation study and an electronic-mail emotion/adoption study. Information Systems Research, 14(2), 189-217.

Chiu, C. M., Hsu, M. H., Lai, H. C., \& Chang, C. M. (2012). Reexamining the influence of trust on online repeat purchase intention: The moderating role of habit and its antecedents. Decision Support Systems, 53(4), 835-845.

Chung, N., \& Kwon, S. J. (2009). Effect of trust level on mobile banking satisfaction: A multi-group analysis of information system success instruments. Behavior \& Information Technology, 28(6), 549-562.

Cohen, J. (1988). Statistical power analysis for the Behavioral sciences (2nd ed.). Hillsdale: Lawrence Erlbaum Associates.

Collier, J. E., \& Bienstock, C. C. (2006). Measuring service quality in eretailing. Journal of service research, 8(3), 260-275.

Dai, H., Haried, P., \& Salam, A. F. (2011). Antecedents of online service quality, commitment and loyalty. Journal of Computer Information Systems, 52(2), 1-11.

Deng, Z. H., Hong, Z. Y., Ren, C., Zhang, W., \& Xiang, F. (2018). What predicts patients' adoption intention toward mHealth services in China: Empirical study. JMIR mHealth and uHealth, 6(8), e172.

Diamantopoulos, A. (2011). Incorporating formative measures into covariance-based structural equation models. MIS Quarterly, $35(2), 335-358$. 
Diamantopoulos, A., \& Siguaw, J. A. (2006). Formative versus reflective indicators in organizational measure development: A comparison and empirical illustration. British Journal of Management, 17(4), 263-282.

Diamantopoulos, A., Riefler, P., \& Roth, K. P. (2008). Advancing formative measurement models. Journal of business research, 61(12), $1203-1218$

Doney, P. M., \& Cannon, J. P. (1997). An examination of the nature of trust in buyer-seller relationships. Journal of Marketing, 61(2), 3551.

Dulleck, U., \& Kerschbamer, R. (2006). On doctors, mechanics, and computer specialists: The economics of credence goods. Journal of Economic literature, 44(1), 5-42.

Fan, H. M., \& Lederman, R. (2018). Online health communities: How do community members build the trust required to adopt information and form close relationships? European Journal of Information Systems, 27(1), 62-89.

Fang, Y. L., Qureshi, I., Sun, H. S., McCole, P., Ramsey, E., \& Lim, K. H. (2014). Trust, satisfaction, and online repurchase intention: The moderating role of perceived effectiveness of e-commerce institutional mechanisms. MIS Quarterly, 38(2), 407-427.

Featherman, M. S., \& Pavlou, P. A. (2003). Predicting e-services adoption: A perceived risk facets perspective. International Journal of Human-Computer Studies, 59(4), 451-474.

Fornell, C., \& Larcker, D. F. (1981). Evaluating structural equation models with unobservable variables and measurement error. Journal of Marketing Research, 18(1), 39-50.

Gao, L. L., \& Waechter, K. A. (2017). Examining the role of initial trust in user adoption of mobile payment services: An empirical investigation. Information Systems Frontiers, 19(3), 525-548.

Gao, Y. W., Li, H., \& Luo, Y. (2015). An empirical study of wearable technology acceptance in healthcare. Industrial Management \& Data Systems, 115(9), 1704-1723.

Gefen, D., \& Ridings, C. M. (2002). Implementation team responsiveness and user evaluation of customer relationship management: A quasiexperimental design study of social exchange theory. Journal of Management Information Systems, 19(1), 47-69.

Gefen, D., Karahanna, E., \& Straub, D. W. (2003). Trust and TAM in online shopping: An integrated model. MIS Quarterly, 27(1), 51-90.

Gong, X., Zhang, K. Z. K., Chen, C. Y., Cheung, C. M. K., \& Lee, M. K. O. (2020). What drives trust transfer from web to mobile payment services? The dual effects of perceived entitativity. Information \& Management, 57(7), 103250.

Guo, X. T., Zhang, X. F., \& Sun, Y. Q. (2016). The privacypersonalization paradox in mHealth services acceptance of different age groups. Electronic Commerce Research and Applications, 16, $55-65$.

Heinze, J., \& Matt, C. (2018). Reducing the service deficit in M-commerce: How service-technology fit can support digital sales of complex products. International Journal of Electronic Commerce, 22(3), 386-418.

Hernandez, J. M. D., Wright, S. A., \& Affonso, F. M. (2019). The importance of advertising skepticism for brand extension appeals. Psychology \& Marketing, 36(7), 687-699.

Hoffmann, C. P., Lutz, C., \& Meckel, M. (2014). Digital natives or digital immigrants? The impact of user characteristics on online trust. Journal of Management Information Systems, 31(3), 138-171.

Hoque, M. R., Bao, Y. K., \& Sorwarb, G. (2017). Investigating factors influencing the adoption of e-health in developing countries: A patient's perspective. Informatics for Health \& Social Care, 42(1), 117. https://doi.org/10.3109/17538157.2015.10755412015.1075541.

Hult, G. T. M., Hair, J. F., Proksch, D., Sarstedt, M., Pinkwart, A., \& Ringle, C. M. (2018). Addressing endogeneity in international marketing applications of partial least squares structural equation modeling. Journal of International Marketing, 26(3), 1-21.
Jarvenpaa, S. L., Shaw, T. R., \& Staples, D. S. (2004). Toward contextualized theories of trust: The role of trust in global virtual teams. Information Systems Research, 15(3), 250-267.

Kim, D. J. (2014). A study of the multilevel and dynamic nature of trust in e-commerce from a cross-stage perspective. International Journal of Electronic Commerce, 19(1), 11-64.

Kim, D. J., Ferrin, D. L., \& Rao, H. R. (2008). A trust-based consumer decision-making model in electronic commerce: The role of trust, perceived risk, and their antecedents. Decision Support Systems, 44(2), 544-564.

Kim, D. J., Ferrin, D. L., \& Rao, H. R. (2009). Trust and satisfaction, two stepping stones for successful e-commerce relationships: A longitudinal exploration. Information Systems Research, 20(2), 237-257.

Komiak, S. Y. X., \& Benbasat, I. (2006). The effects of personalization and familiarity on trust and adoption of recommendation agents. MIS Quarterly, 30(4), 941-960.

Lankton, N. K., McKnight, D. H., \& Tripp, J. (2015). Technology, humanness, and trust: Rethinking trust in technology. Journal of the Association for Information Systems, 16(10), 880-918.

Lee, S. T., Dutta, M. J., Lin, J. L., Luk, P., \& Kaur-Gill, S. (2018). Trust ecologies and channel complementarity for information seeking in cancer prevention. Journal of Health Communication, 23(3), 254 263.

Li, H., \& Suomi, R. (2009). A proposed scale for measuring e-service quality. International Journal of $u$-and e-Service, Science and Technology, 2(1), 1-10.

Lippert, S. (2007). Investigating postadoption utilization: An examination into the role of interorganizational and technology trust. IEEE Transactions on Engineering Management, 54(3), 468-483.

Liu, X. X., Guo, X. T., Wu, H., \& Wu, T. S. (2016). The impact of individual and organizational reputation on physicians' appointments online. International Journal of Electronic Commerce, 20(4), 551-577.

Lu, X. Y., Zhang, R. T., Wu, W., Shang, X. P., \& Liu, M. L. (2018). Relationship between internet health information and patient compliance based on trust: Empirical study. Journal of Medical Internet Research, 20(8), e253.

Mayer, R. C., Davis, J. H., \& Schoorman, F. D. (1995). An integrative model of organizational trust. Academy of Management Review, 20(3), 709-734.

McKnight, D. H., \& Chervany, N. L. (2001). What trust means in ecommerce customer relationships: An interdisciplinary conceptual typology. International Journal of Electronic Commerce, 6(2), 3559.

McKnight, D. H., Choudhury, V., \& Kacmar, C. (2002). Developing and validating trust measures for e-commerce: An integrative typology. Information Systems Research, 13(3), 334-359.

Mcknight, D. H., Carter, M., Thatcher, J. B., \& Clay, P. F. (2011). Trust in a specific technology: An investigation of its components and measures. ACM Trans. Manage. Inf. Syst., 2(2), 1-25.

Meng, F. B., Guo, X. T., Peng, Z. Y., Lai, K. H., \& Zhao, X. L. (2019a). Investigating the adoption of mobile health services by elderly users: Trust transfer model and survey study. JMIR mHealth and uHealth, 7(1), e12269.

Meng, F. B., Guo, X. T., Peng, Z. Y., Lai, K. H., \& Zhao, X. L. (2019b). Investigating the adoption of mobile health services by elderly users: Trust transfer model and survey study. JMIR mHealth and uHealth, $7(1), 1-10$.

Mohr, H., \& Walter, Z. (2019). Formation of Consumers' perceived information security: Examining the transfer of Trust in Online Retailers. Information Systems Frontiers, 21(6), 1231-1250.

Mou, J., \& Cohen, J. F. (2017). Trust and online consumer health service success: A longitudinal study. Information Development, 33(2), 169-189. 
Mou, J., Shin, D. H., \& Cohen, J. (2016). Health beliefs and the valence framework in health information seeking behaviors. Information Technology \& People, 29(4), 876-900.

Mousavi, R., Chen, R., Kim, D. J., \& Chen, K. C. (2020). Effectiveness of privacy assurance mechanisms in users' privacy protection on social networking sites from the perspective of protection motivation theory. Decision Support Systems, 135, 113323.

Mpinganjira, M. (2018). Precursors of trust in virtual health communities: A hierarchical investigation. Information \& Management, 55(6), 686-694.

Nowak, K. L., \& Rauh, C. (2005). The influence of the avatar on online perceptions of anthropomorphism, androgyny, credibility, homophily, and attraction. Journal of Computer-Mediated Communication, 11(1), 153-178.

Nunnally, J. C., \& Bernstein, I. H. (1994). Psychometric theory (3d ed.). New York: McGraw-Hill.

O'Connor, Y., \& O'Reilly, P. (2018). Examining the infusion of mobile technology by healthcare practitioners in a hospital setting. Information Systems Frontiers, 20(6), 1297-1317.

Odusanya, K., Aluko, O., \& Lal, B. (2020). Building Consumers' Trust in electronic retail platforms in the sub-Saharan context: An exploratory study on drivers and impact on continuance intention. Information Systems Frontiers, 15. https://doi.org/10.1007/s10796020-10043-2.

Oliver, R. L., \& Burke, R. R. (1999). Expectation processes in satisfaction formation a field study. Journal of Service Research, 1(3), 196-214.

Ou, C. X., Pavlou, P. A., \& Davison, R. M. (2014). Swift guanxi in online marketplaces: The role of computer-mediated communication technologies. MIS Quarterly, 38(1), 209-230.

Ozdemir, Z. D. (2007). Optimal multi-channel delivery of expertise: An economic analysis. International Journal of Electronic Commerce, 11(3), 89-105.

Park, H., \& Lee, T. (2018). Adoption of e-government applications for public health risk communication: Government trust and social media competence as primary drivers. Journal of Health Communication, 23(8), 712-723.

Pavlou, P. A., \& Fygenson, M. (2006). Understanding and predicting electronic commerce adoption: An extension of the theory of planned behavior. MIS Quarterly, 30(1), 115-143.

Pavlou, P. A., Liang, H. G., \& Xue, Y. J. (2007). Understanding and mitigating uncertainty in online exchange relationships: A principal-agent perspective. MIS Quarterly, 31(1), 105-136.

Peter, J. P., \& Tarpey, L. X. (1975). A comparative analysis of three consumer decision strategies. Journal of Consumer Research, 2(1), 29-37.

Podsakoff, P., \& Organ, D. (1986). Self-reports in organizational research: Problems and prospects. Journal of Management, 12(4), 531-533.

Podsakoff, P. M., MacKenzie, S. B., Lee, J. Y., \& Podsakoff, N. P. (2003). Common method biases in behavioral research: A critical review of the literature and recommended remedies. Journal of Applied Psychology, 88(5), 879-903.

Preacher, K. J., \& Hayes, A. F. (2008). Asymptotic and resampling strategies for assessing and comparing indirect effects in multiple mediator models. Behavior Research Methods, 40(3), 879-891.

Rönkkö, M., \& Ylitalo, J. (2011). PLS marker variable approach to diagnosing and controlling for method variance. Shanghai: Thirty Second International Conference on Information Systems.

Sarstedt, M., \& Mooi, E. A. (2014). A concise guide to market research: The process, data, and methods using IBM SPSS statistics. Heidelberg: Springer.

Sollner, M., Hoffmann, A., \& Leimeister, J. M. (2016). Why different trust relationships matter for information systems users. European Journal of Information Systems, 25(3), 274-287.

Tams, S., Thatcher, J. B., \& Craig, K. (2018). How and why trust matters in post-adoptive usage: The mediating roles of internal and external self-efficacy. Journal of Strategic Information Systems, 27(2), 170 190.

Torkzadeh, G., \& Dhillon, G. (2002). Measuring factors that influence the success of internet commerce. Information Systems Research, 13(2), 187-204.

van Velsen, L., Tabak, M., \& Hermens, H. (2017). Measuring patient trust in telemedicine services: Development of a survey instrument and its validation for an anticoagulation web-service. International Journal of Medical Informatics, 97, 52-58.

Vance, A., Elie-Dit-Cosaque, C., \& Straub, D. W. (2008). Examining trust in information technology artifacts: The effects of system quality and culture. Journal of Management Information Systems, 24(4), 73-100.

Venkatesh, V., Thong, J. Y. L., Chan, F. K. Y., \& Hu, P. J. H. (2016) Managing citizens' uncertainty in e-government services: The mediating and moderating roles of transparency and trust. Information Systems Research, 27(1), 87-111.

Wang, W. Q., \& Benbasat, I. (2007). Recommendation agents for electronic commerce: Effects of explanation facilities on trusting beliefs. Journal of Management Information Systems, 23(4), 217-246.

Wang, W. Q., \& Benbasat, I. (2016). Empirical assessment of alternative designs for enhancing different types of trusting beliefs in online recommendation agents. Journal of Management Information Systems, 33(3), 744-775.

Wang, W. Q., Qiu, L. Y., Kim, D. M., \& Benbasat, I. (2016). Effects of rational and social appeals of online recommendation agents on cognition- and affect-based trust. Decision Support Systems, 86, $48-60$.

Wixom, B. H., \& Watson, H. J. (2001). An empirical investigation of the factors affecting data warehousing success. MIS Quarterly, 25(1), $17-41$.

Xu, J. J., Cenfetelli, R. T., \& Aquino, K. (2016). Do different kinds of trust matter? An examination of the three trusting beliefs on satisfaction and purchase behavior in the buyer-seller context. Journal of Strategic Information Systems, 25(1), 15-31.

Yang, M., Yuan, F., \& Jiang, J. (2020). When Does Trust Reinforce Intentions to Upgrade to Paid Online Healthcare Consultations? The Valence of Platform-Versus Service-Related Attitudes. PACIS 2020 Proceedings., 11.

Ye, H., \& Kankanhalli, A. (2017). Solvers' participation in crowdsourcing platforms: Examining the impacts of trust, and benefit and cost factors. Journal of Strategic Information Systems, 26(2), 101-117.

Zahedi, F. M., Walia, N., \& Jain, H. (2016). Augmented virtual doctor office: Theory-based design and assessment. Journal of Management Information Systems, 33(3), 776-808.

Zhang, M., Guo, X. T., \& Wu, T. S. (2019). Impact of free contributions on private benefits in online healthcare communities. International Journal of Electronic Commerce, 23(4), 492-523.

Publisher's Note Springer Nature remains neutral with regard to jurisdictional claims in published maps and institutional affiliations.

Ming Yang is an associate professor of information management at Central University of Finance and Economics. He earned his Ph.D. in MIS from Harbin Institute of Technology. Dr. Yang's research interests are in multidisciplinary areas such as online healthcare, digital business strategy, and medical data analytics. His work has been published or is forthcoming in refereed journals and conference proceedings, including Information Systems Frontiers, Journal of American Society for Information and Technology, Journal of Biomedical Informatics, and Information Processing and Management. 
Jinglu Jiang is an assistant professor in MIS at Binghamton University. She earned her Ph.D. in management from HEC Montreal (Canada). Her main research interests include digital healthcare, human-IT interaction, and personal informatics. Her research appears in MIS Quarterly, MIT Sloan Management Review, Information Processing \& Management, JMIR Medical Informatics, and others.

Melody Y. Kiang is a Professor of Computer Information Systems at California State University, Long Beach.She received her Ph.D. in MSIS from the University of Texas at Austin.Prior to joining CSULB, she was Associate Professor at Arizona State University.Her research interests include data analysis, the development and applications of AI/
Machine Learning techniques to a variety of business problems, and eCommerce related research.Her research has appeared in Information Systems Research (ISR), Management Science, Journal of Management Information Systems (JMIS), Decision Support Systems (DSS), IEEE Transactions on SMC, EJOR, the Journal of Operational Research Society, and other professional journals.She is Editor-in-Chief of the Journal of Electronic Commerce Research (JECR).

Fangyun Yuan is a postgraduate student at Central University of Finance and Economics. Her research focuses on digital healthcare and online trust issues. 